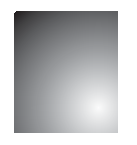

\title{
Comportamento do Consumidor: avaliação de ALTERNATIVAS E BUSCA DE INFORMAÇÃO NA ESCOLHA DE CURSos superiores em CiÊnCia da Computação
}

\author{
Consumer Behavior: evaluation of alternatives and search \\ for information in the choice of higher education courses in \\ Computer Science
}

Érica Fernanda da Silva Kalil

Mestre pelo Programa de Mestrado em Administração, Universidade FUMEC - Belo Horizonte - MG, Brasil.

E-mail: ericakalil@hotmail.com

\section{Cid Gonçalves Filho}

Coordenador do Programa de Doutorado em Administração da Universidade FUMEC - Belo Horizonte - MG, Brasil.

E-mail:cid@fumec.br

\section{Resumo}

A computação, além de ser base dos diversos sistemas web, é responsável por um número crescente de empregos e pela geração de riqueza. O objetivo deste trabalho é avaliar o comportamento do consumidor (alunos de graduação) na escolha do curso de Ciência da Computação nas fases de busca de informação e avaliação das alternativas. A amostra contou com 208 questionários por meio de pesquisa quantitativa. A internet foi a ferramenta mais utilizada no processo de busca de informação. Na avaliação das alternativas, a escolha do curso está relacionada a fatores profissionais, sociais, pessoais e de conveniência, e que, para escolha da IES, pesam o valor do diploma no mercado, a marca e reputação, a qualidade de ensino, os professores e a infraestrutura. Para a academia, o artigo provê evidências empíricas do comportamento do consumidor, propondo um modelo explicativo de escolha de IES e um modelo hipotético de impacto da satisfação do aluno em suas intenções comportamentais.

Palavras-chave: Comportamento do consumidor. Instituições de Educação Superior (IES). Ciência da Computação.

\section{Abstract}

Computer Science is basis of many web systems, and is also responsible for a growing number of jobs and wealth creation. The aim of this study was to understand the consumer behavior (undergraduate students) decision making of Higher Education Institutions at the stages of information search and evaluation of alternatives. The sample consisted of 208 questionnaires collected through quantitative research. The Internet was the most used tool for the process of information search. In the evaluation of alternatives, the choice of course is related to professional factors, social elements, and personal convenience, and that the choice of Faculty is decided thought the evaluation of the value of the diploma in the market, brand reputation, quality of education, teachers and infrastructure. The article provides empirical evidence of consumer behavior, proposing an explanatory model about the choice of Higher Education Institutions and a hypothetical model the impact of student satisfaction in their behavioral intentions.

Key word: Consumer behavior. Higher Education Institutions. Computer Science. 


\section{INTRODUÇÃO}

Compreender o comportamento do consumidor passou a ser objeto de estudo de vários pesquisadores, pois, cada vez mais, esse campo recebe "[...] adeptos de diversas áreas, tais como macro e microeconomia, psicologia, antropologia, sociologia, dentre outros" (VIEIRA, 2003, p. 2). A definição do comportamento do consumidor, segundo Vieira (2002, p. 5), corresponde "[...] à investigação das atividades diretamente envolvidas em obter, consumir e dispor de produtos e serviços, incluindo os processos decisórios que antecedem e sucedem estas ações [...]", ou seja, é o estudo do processo vivido pelos indivíduos ao tomarem decisões de empregar seus recursos em itens relacionados ao consumo, fazendo assim uma vinculação com os propósitos dos profissionais de marketing, que buscam identificar as necessidades e induzir o cliente a consumir o produto (VIEIRA, 2002, p. 5). Para Dubois (1991), "[...] mais do que nunca, compreender o consumidor é uma necessidade vital não apenas para as empresas, mas para toda a organização/instituição que se assuma como orientada para os clientes". Engel, Blackwell e Miniard (2000, p. 4) defendem que o comportamento do consumidor compreende "[...] as atividades diretamente envolvidas em obter, consumir e dispor de produtos e serviços, incluindo os processos decisórios que antecedem e sucedem estas ações". Matheus (2005, p. 1) porém, sustenta que é o "[...] tema chave de sustentação de toda a atividade mercadológica realizada com intuito de desenvolver, promover e vender produtos".

É necessário frisar que, cada vez mais, estudos são voltados para esse campo e que compreender como os consumidores tomam suas decisões para adquirir ou utilizar os produtos é de suma importância para otimizar a eficácia e a eficiência das atividades de marketing. No que tange à educação, o processo de tomada de decisão é bastante complexo, pois a aquisição do produto educação/formação apresenta componentes emocionais, riscos econômicos e de desempenho e riscos psicológicos. O risco econômico vem associado ao valor $e$ à qualidade do produto ofertado, o risco de desempenho está ligado à performance das instituições, aliado ao sentimento de o produto atender ou não às expectativas geradas e aos benefícios desejados, já o risco psicológico está rela- cionado ao fato de o objeto de aquisição não refletir a imagem que ele deseja retratar (MATHEUS, 2005, p. 1-2). Com base nas teorias do comportamento do consumidor, buscou-se descrever, neste trabalho, como ocorrem as etapas de avaliação de alternativas e busca de informações de estudantes de cursos superiores em Ciência da Computação.

Sobre o setor de computação, pode-se dizer que ele compreende uma área em constante crescimento e de importante papel no âmbito profissional, comercial, industrial, científico e pessoal (UNIVERSIDADE PASSO FUNDO, 2010). Decidir ser profissional dessa área envolve graduar-se em Ciência da Computação, um curso mundialmente conhecido e um dos principais na área de tecnologia da informação (TI). A aplicação da informática nas instituições de ensino, pesquisas, setores industriais, agroindustriais e demais setores públicos e privados é um dos fatores que justificam esta pesquisa. O campo de atuação do profissional em Ciência da Computação é amplamente diversificado, pois o bacharel tem a capacidade de elaborar os mais diversos softwares, desde sistemas de gestão até aplicativos para web e celulares, podendo atuar na indústria, bancos, comércio, hospitais e todos os lugares que necessitem da automatização de seus negócios. Profissionais formados nessa área são preparados para resolver problemas reais, aplicando soluções que envolvam computação, independente do ambiente onde está inserido (ALECRIM, 2007). Atuando também no desenvolvimento de sistemas de computação, banco de dados, rede de computadores, telecomunicação, infraestrutura de tecnologia da informação (TI), sistema da informação, desenvolvimento de softwares, dentre outros espaços de abrangência da Ciência da Computação (UNIVERSIDADE PASSO FUNDO, 2010). O auxilio ao usuário na compra do equipamento que atenda às suas necessidades, a prestação de assessoria e consultoria a empresas de pequeno e médio porte, também fazem parte do leque de possibilidades de atuação do graduado em ciência da computação (Universidade Anhembi Morumbi, 2010).

Pesquisas bibliográficas na área de comportamento do consumidor por escolha de cursos superiores, Instituições de Educação Superior (IES) e sobre a educação foram efetuadas nas literaturas, artigos científicos, trabalhos de pesquisa, bibliotecas de teses e dissertações das IES, análises teóricas e resenhas bi- 
bliográficas publicadas na Revista de Administração de Empresas (RAE), Revista de Administração Contemporânea (RAC), Revista de Administração da Universidade de São Paulo (RAUSP) e no Encontro da Associação Nacional de Pós-Graduação e Pesquisa em Administração (EnANPAD). O resultado demonstrou uma ampla variedade de estudos científicos e de trabalhos publicados sobre o tema comportamento do consumidor, porém, há campos ainda não explorados, devido à grande parte deles não estar propriamente vinculada ao comportamento do consumidor e sim a áreas como estratégia das organizações, comportamento organizacional e também outras áreas compreendidas pelo marketing. Pesquisas paralelas revelaram a existência de publicações voltadas para alunos/estudantes das IES, imagem das IES, cursos de pós-graduação e de graduação em administração e para o ensino superior. Nesse contexto, pode-se citar o trabalho de Coelho (2007) que discorreu sobre o comportamento dos atuais e futuros alunos do curso de pós-graduação lato sensu em Administração por meio da descrição dos critérios utilizados pelos consumidores na hora de escolher uma IES para ingressar em um curso de pós-graduação em administração (COELHO, 2007, p. 17). O trabalho de Melo (2009) investigou a satisfação de discentes quanto ao uso dos serviços de uma Instituição de Ensino Superior (IES) privada, considerando a influência dos estímulos ambientais com maior grau de existência e as emoções vivenciadas no campus (MELO, 2009, p. 10). Já Martins (2006), procurou "[...] conhecer o processo decisório de prospects que prestaram o vestibular para o curso de administração em instituições de ensino superior da cidade de Belo Horizonte, estado de Minas Gerais" (MARTINS, 2006, p. 5). Outras pesquisas relacionadas ao tema, porém com assuntos voltados para alunos e estudantes das IES, com enfoque no marketing de relacionamento, revelou o trabalho de Marques (2008), que teve como objetivo avaliar a lealdade dos clientes/consumidores através da análise da qualidade percebida, confiança e comprometimento. Ainda sobre lealdade, o autor Soares (2007, p. 18) propôs

[...] identificar os antecedentes da lealdade organizados em uma cadeia nomológica estruturada no que se refere à pós-graduação lato sensu, em instituições de ensino superior privado no cenário brasileiro.
O artigo de Fonseca (2009) visou compreender o que motiva os jovens a buscarem uma formação superior imediatamente após sua conclusão do ensino médio, fazendo com que as IES direcionem suas ações de modo a conquistar esse público. (FONSECA, 2009, p. 85). A ideia principal do trabalho de Falcão (2007, p. 18) visava entender como os atributos da diversidade no relacionamento e no desempenho de alunos de graduação em Administração em uma Instituição de Ensino Superior privada, podem influenciar na formação de grupos e no desempenho dos indivíduos que fazem parte de um mesmo ambiente social. Apesar da importância do estudo do comportamento do consumidor para as organizações, da relevância do setor de educação superior e do curso de Ciência da Computação para as IES e para o desenvolvimento do país, poucos foram os trabalhos encontrados sobre o comportamento do consumidor de cursos de graduação. Considerando a escassez de estudos nessa área e o fato de que nenhuma das pesquisas realizadas em periódicos nacionais, banco de teses de dissertações $e$ anais de eventos fazia referência especificamente a cursos de Ciência da Computação, pode-se concluir que há uma lacuna de estudos que busquem identificar o comportamento dos consumidores desses serviços. Desse modo, com o objetivo de compreender o processo de decisão de alternativa de compra, busca de informações, bem como o comportamento na fase de consumo de alunos de ciência da computação, foi proposta esta pesquisa.

Para um maior entendimento sobre o processo de avaliação dos alunos de cursos de Ciência da Computação nas fases de busca de informação $e$ avaliação das alternativas, de forma a identificar as principais fontes de informação para a escolha da IES e verificar os elementos de maior relevância na escolha do curso e IES, foram aplicados 208 questionários no primeiro semestre de 2010, através do método tipo survey, aos alunos do curso de Ciência da Computação, do primeiro ao último período, de uma IES privada na cidade de Belo Horizonte, por meio de coleta pessoal. Utilizou-se como base o modelo do processo decisório de compra de Engel, Blackwell, Miniard (1995, 2000) e o modelo hipotético da fase de consumo proposto por Fornell et al. (1992).

A estrutura deste artigo está distribuída em introdução, revisão de literatura sobre o comportamento do 
consumidor, o ensino superior no Brasil e o curso de Ciência da Computação, metodologia e análise dos resultados. E, por último, apresentaram-se as conclusões obtidas e as limitações e recomendações para os futuros trabalhos nessa área.

\section{Comportamento do Consumidor}

A área de comportamento do consumidor aguça o interesse de estudiosos do marketing devido à sua complexidade e importância, pois os profissionais dessa área devem aprofundar estudos sobre as ciências comportamentais a fim de entender os consumidores e seus comportamentos nas fases de planejamento de compra e no processo de compra propriamente dito (SAMPAIO et al., 2004, p. 5). De acordo com Richers (1984, p. 46), "[...] nenhuma faceta do marketing mereceu, até hoje, tanta atenção pela pesquisa científica quanto o comportamento do consumidor". Nos últimos anos muito se aprendeu sobre os aspectos motivacionais do consumidor através das pesquisas conduzidas em torno da personalidade e do comportamento. Mesmo não se obtendo informações esclarecedoras, essas pesquisas indicaram caminhos úteis para os pesquisadores e administradores compreenderem as atividades mentais e emocionais realizadas na seleção, compra e uso de produtos/serviços para satisfazer as necessidades e desejos dos consumidores (RICHERS, 1984, p. 46). Conforme Kotler (2000, p. 182), o campo de estudos sobre o comportamento do consumidor abrange, a forma pela qual as "[...] pessoas, grupos e organizações selecionam, compram, usam e descartam artigos, idéias ou experiências para satisfazer suas necessidades e seus desejos [...]".

Para Sheth, Mittal e Newman (2001, p. 29), o comportamento do consumidor

[...] é definido como as atividades físicas e mentais realizadas por clientes de bens de consumo $e$ industriais que resultam em decisões e ações, como comprar e utilizar produtos e serviços, bem como pagar por eles.

Para Engel, Blackwell e Miniard (1995, p. 8) “[...] entender e adaptar-se à motivação e comportamento do consumidor não é uma opção, é a necessidade absoluta para a sobrevivência competitiva". Os autores citam princípios básicos para compreender o comportamento do consumidor, tais como: 1 - entender que qualquer produto ou serviço deve satisfazer as necessidades do consumidor e não as necessidades e expectativas da equipe administrativa ou do diretor movido pelo ego gerencial; 2 - compreender que o consumidor tem vontade própria e não é tão facilmente manipulado: os produtos ou serviços são aceitos ou rejeitados com base na extensão em que eles sejam percebidos, seja direta ou indiretamente, como relevantes às necessidades e ao estilo de vida de cada um (ENGEL, BLACKWELL; MINIARD, 1995, p. 8). Já Sampaio et al. (2004) afirma que conhecer os consumidores de diferentes costumes, culturas e personalidades torna-se importante para que os tomadores de decisão possam estruturar o lançamento e o desenvolvimento de novos produtos no mercado, pois

[...] as organizações precisam entender melhor como seus atuais e potenciais consumidores pensam, trabalham, se divertem, e como são influenciados por outros indivíduos e grupos. (SAMPAIO et al., 2004, p. 3)

Um modelo completo de comportamento do consumidor deve abranger segundo Terci (2001, p. 93): a) a influência dos grupos e atividades no comportamento do consumidor, como a cultura, a subcultura, a família, a classe social e o estilo de vida; b) a análise das forças individuais no comportamento de consumo, como a aprendizagem e experiência, o processo de avaliação, as atitudes e a mudança, os processos de informação $e$ a personalidade e, por último, a análise do processo de decisão do consumidor, que envolve o reconhecimento do problema, a busca de informações, a avaliação de alternativas, o processo de compra e comportamentos pós-compra.

Diante da crescente necessidade e interesse por parte das organizações em encontrar estratégias eficazes para influenciar o comportamento do consumidor, verifica-se um grande investimento em estudos nessa área. De acordo com Sheth, Mittal e Newman (2008, p. 32), o entendimento do comportamento do cliente pode ser visto como a chave para o sucesso das empresas, pois estudar o comportamento do cliente significa adquirir conhecimentos básicos necessários para se tomar uma decisão empresarial de sucesso. Faz-se necessário também monitorar o processo decisório de 
escolha do consumidor, de acordo com Kotler e Keller (2006), e este deve ser um trabalho constante, uma vez que o propósito do marketing centra-se em atender e satisfazer às necessidades $e$ aos desejos dos consumidores, tornando fundamental conhecer o processo decisório de escolha dos consumidores.

\section{Fatores que Influenciam Processo Decisório de Escolha do Consumidor}

Vários são os fatores internos e externos que influenciam o processo de tomada de decisão por compra dos consumidores (ENGEL; BLACKWELL; MINIARD, 2000; CHURCHILL; PETER, 2000; SCHIFFMAN, KANUK, 2000; SOLOMON, 2002; KOTLER, KELLER, 2006). O comportamento do consumidor possui uma dinâmica complexa e que engloba um processo iniciado por motivação, influenciado por fatores intrínsecos e extrínsecos, no qual o consumidor assume papéis intercambiáveis de comprador, influenciador e utilizador, que podem existir isolados ou conjuntamente. Esse comportamento deve ser observado e entendido dentro de um contexto ambiental de referência que envolve a estrutura social e os grupos dos quais o consumidor participa. (TERCI, 2001, p. 95)

As influências ambientais, as diferenças individuais e os processos psicológicos compõem as variáveis que moldam a tomada de decisão, segundo Engel, Blackwell e Miniard (2000), já que, nas diferenças individuais, verificam-se os recursos do consumidor, o conhecimento, as atitudes a motivação, a personalidade, os valores e o estilo de vida. Já as influências ambientais são demonstradas por meio da cultura, da classe social, da influência pessoal, da família e da situação econômica. Para os processos psicológicos, os autores citam o processamento de informação, a aprendizagem e a mudança de atitude e comportamento (ENGEL; BLACKWELL; MINIARD, 2000, p. 93). Solomon (2002), Schiffman e Kanuk (2000), por sua vez, afirmam que o consumidor sofre influências psicológicas, pessoais, sociais e culturais.

Para análise das influências sofridas pelos consumidores no processo de compra, Kotler (1998) apresentou seu modelo dividido em fatores culturais, sociais, pessoais e psicológicos. Nos quesitos culturais são observadas características como cultura, subcultura e classes sociais.
Já para a parte social, levam-se em consideração grupos de referência, família e papéis e posições sociais. No âmbito pessoal, a idade e o estágio do ciclo de vida, a ocupação, condições econômicas, estilo de vida e personalidade são os fatores de análise. E por último, os fatores psicológicos levam em conta a motivação, a percepção, a aprendizagem $e$ as crenças $e$ atitudes (KOTLER, 1998, p. 163). Conforme os elementos do estudo do comportamento do consumidor atribuídos à perspectiva de influências sociais e interpessoais, têm-se, segundo Terci (2001), os valores, as atitudes, a simbologia do consumo, "[...] onde bases antropológicas de estudo subsidiam a compreensão do âmbito cultural do comportamento do consumidor." (TERCI, 2001, p. 95)

\section{Processo Decisório de Compra: BUSCA DE INFORMAÇÃO E AVALIAÇÃO DAS ALTERNATIVAS}

O processo decisório de compra envolve o reconhecimento da necessidade, a busca de informações, a avaliação de alternativas, a decisão de compra e os sentimentos do pós-compra. É imprescindível distinguir os conceitos de necessidades e de desejos dos clientes, pois a satisfação de ambos são objetivos importantes a serem atingidos pelas organizações. A necessidade "[...] é a condição insatisfatória de um cliente, que o leva a uma ação que tornará essa condição melhor" (SHETH; MITTAL; NEWMAN, 2008, p. 59), ou seja, a necessidade nasce de um desconforto nas condições físicas ou psicológicas da pessoa. Já os desejos podem ser descritos como algo além do estado de conforto mínimo, uma diferenciação, em outras palavras, "[...] a vontade de obter produtos ou serviços melhores ou em maior quantidade" (SHETH; MITTAL; NEWMAN, 2008, p. 59). O reconhecimento da necessidade é o primeiro item a ser avaliado no processo de tomada de decisão, associando-se à comparação entre o que o consumidor pensa ser a situação ideal e o que é a situação real, ou seja,

[...] é o estágio que inicia um processo decisório que, por sua vez, ocorre através da interação de diferenças individuais como valores e necessidades e influências ambientais, particularmente a interação social. (ENGEL; BLACKWELL; MINIARD, 2000, p. 96) 
Seguindo o propósito desse artigo, serão descritas as etapas de busca de informação e avaliação das alternativas.

\subsection{Busca de Informação}

A busca de informação envolve a atenção do consumidor quanto à reunião de informações sobre o produto ou serviço a ser adquirido ou consumido, em que tais informações serão de grande valor no processo de avaliação e decisão (TERCI, 2001, p. 98). De acordo com Block e Roering (1976), o processo de informação do consumidor se dá através de quatro fases, sendo elas: a exposição, atenção, compreensão $e$ a retenção da informação, em que as informações podem advir de fontes interpessoais, de veículos de comunicação e de experiências com o produto ou serviço. É importante frisar que a identificação de diversas fontes de informação utilizadas pelos consumidores para conhecimento dos produtos ou serviços tem especial relevância para as atividades de comunicação e marketing. Nesse contexto, faz-se necessário trabalhar com diversas fontes para averiguar o veículo de comunicação mais indicado para determinado produto ou serviço de acordo com suas características, número de informações e o grau de envolvimento, devendo considerar também as fontes de comunicação interpessoais, que são importantes no processo de busca de informação, avaliação e decisão de compra. (TERCI, 2001, p. 98)

Outro conceito atribuído ao processo de busca pode ser entendido como a "[...] ativação motivada de conhecimento armazenado na memória ou de aquisição de informação do ambiente" (ENGEL; BLACKWELL; MINIARD, 2000, p. 119-120), ou seja, uma busca interna ou externa. Faz-se importante avaliar também as estratégias de busca de informação de acordo com o seu grau, direção e sequência. De acordo com Engel, Blackwell e Miniard (2000), compreende-se por grau de busca a quantidade total de busca realizada de acordo com o número de marcas, lojas, atributos $e$ fontes de informação consideradas durante a busca como também o tempo gasto nessa realização. Já a direção representa o conteúdo específico da busca, enfatizando as marcas e lojas específicas e não somente o número delas. Para a dimensão sequência, leva-se em conta a ordem de ocorrência das atividades de busca. (ENGEL; BLACKWELL; MINIARD, 2000, p. 121)
As contribuições do processo da busca de informações podem ser descritas a partir da vertente de que é por meio da busca de informações que se procura minimizar as dúvidas de comprar ou não um produto. Richers (1984, p. 48) afirma que

[...] a busca pode ser largamente inconsciente ou, pelo contrário, envolver intensos estudos, por exemplo, ao confrontarmos duas marcas distintas de um produto sofisticado, com características semelhantes.

Richers (1984) relata ainda que a busca engloba desde um rápido olhar de uma dona de casa para uma prateleira num supermercado, até a investigação de catálogos ou visitas a showrooms de um amador de música, interessado em comprar um equipamento que mais se ajuste ao seu gosto e poder aquisitivo. As informações armazenadas na memória do indivíduo, as consultas às fontes externas (como outros consumidores ou a opinião de uma pessoa respeitada) $e$ o confronto entre marcas competitivas compóem as principais fontes de referência para o processo de busca. No processo de busca, o confronto entre marcas é o passo mais fácil e convincente para a tomada de decisão, pois permite a contraposição direta entre produtos, em termos de sua apresentação, seu conteúdo, sua capacidade de gerar determinados efeitos e certamente os seus preços. (RICHERS, 1984, p. 48)

\subsection{Avaliação das Alternativas}

Após o processo de busca de informação, o consumidor deverá avaliar as alternativas encontradas por meio dos quesitos de comparação entre preços, marca e qualidade, avaliação de bens e serviços, marcas e locais de negócios, levando-se em conta que

[...] os critérios de avaliação são variáveis entre as pessoas e o ambiente envolvido, sofrendo quatro grandes forças: personalidade, fatores sociais, variáveis demográficas e mercado. (TERCI, 2001, p. 98)

Terci (2001) relata ainda que o processo de avaliação parte do processamento das informações que o consumidor possui, sendo elas julgadas em termos de atividades, imagem e regras de decisão próprias, para 
[...] constituir um referencial de preferências, onde benefícios específicos são buscados pelo consumidor e os atributos do produto deverão proporcionar estes benefícios e satisfazer as necessidades. (TERCI, 2001, p. 98)

$\mathrm{Na}$ fase de avaliação de alternativa pré-compra, o consumidor busca tomar uma decisão diante das várias informações coletadas a respeito do produto ou serviço desejado. Para isso, levam-se em consideração alguns critérios de avaliação e seus determinantes, a avaliação das alternativas escolhidas e a seleção de uma regra de decisão. Discutir a avaliação de alternativa pré-compra compreende examinar os atributos do produto conforme seu padrão e especificação, em que os critérios de avaliação representam as dimensões ou atributos particulares que são usados no julgamento das alternativas de escolha, podendo eles vir representados através de fatores como segurança, confiabilidade, preço, nome da marca, país de origem, garantia e quilometragem por litro na compra de um carro, por exemplo. Os consumidores muitas vezes consideram critérios hedonistas como sentimentos que advêm da posse, representados por meio do prestígio e status, de alegria e excitação. (ENGEL; BLACKWELL; MINIARD, 2000, p. 136)

No processo de tomada de decisão são citados os fatores situacionais (localização e situação final de destino do produto), a similaridade de alternativas de escolha (preço, status, divertimento, necessidade), a motivação (utilitárias ou hedonistas), o envolvimento e o conhecimento (consumidores bem informados ou não) como critérios de avaliação usados antes da decisão final sobre o que se deseja (ENGEL; BLACKWELL; MINIARD, 2000, p. 138-140). Os consumidores avaliam as alternativas de escolha pelo de julgamentos ou crenças, internas e externas, sobre o desempenho das alternativas levadas em consideração. Tal seleção pode também ser feita com o uso de sugestões ou sinais e de cortes, descritos como "[...] uma restrição ou um requisito para valores aceitáveis do atributo". (ENGEL; BLACKWELL; MINIARD, 2000, p. 142)

Como elemento final do processo de avaliação de alternativa pré-compra tem-se a regra de decisão, compreendida como estratégia usada pelos consumidores para fazer seleção das alternativas de escolha. Observa-se grande variação nas regras de decisão, podendo elas serem apresentadas de forma simples, complexa, compensatória e não compensatória. Nos quesitos compensatórios há a predominância dos pontos fortes em detrimento dos pontos fracos, porém os pontos fracos se sobressaem mais em uma análise não compensatória. (ENGEL; BLACKWELL; MINIARD, 2000, p. 143)

\section{Educação Superior e os Cursos da Área de Ciência da Computação}

Diante das mudanças vividas no cenário econômico, político e social e da necessidade de manter-se alinhado a tais alterações, observa-se uma crescente busca da sociedade pelo ensino superior, seja ele por garantia de satisfação pessoal ou qualificação profissional. De acordo com Gavaldon (1996, p. 11), “[...] a realização pessoal tornou-se uma necessidade básica do indivíduo. Sentir-se bem já subentende sentir-se realizado, alcançando objetivos e impondo-se novos, na busca de ser mais, crescer mais e atingir mais". Para Brito (1996, p. 17),

[...] o ensino, enquanto responsável direto pela formação de profissionais, seja ele de nível técnico ou superior, deve considerar a flexibilidade das suas ações educacionais tanto no sentido de elevar a eficiência empresarial quanto de poder garantir a competência formal e política do profissional. (BRITO, 1996, p. 17)

Analisando os desafios enfrentados pelas universidades, Carpinelli (1996, p. 24) afirma que a universidade deve reconhecer que a sua verdadeira função

[..] não é apenas formar profissionais especializados, como também pessoas que possam lidar com máquinas, pessoas, objetos e, acima de tudo, saibam lidar consigo mesmas e com a realidade em que vivem, com o objetivo de torná-las cada vez melhores.

Gavaldon (1996, p. 12) afirma ainda que

[...] na atuação profissional aplica o conhecimento adquirido, expande suas opções de trabalho, reflete sobre o próprio desempenho e constata sua transformação, ratificando, desse modo, a satisfação. 
O crescimento do setor de educação superior no Brasil pode ser comprovado por meio dos resultados de pesquisas realizadas pelo Instituto Nacional de Estudos e Pesquisas Educacionais (INEP) publicadas no Censo de Educação Superior (2008). No período compreendido entre 2002 a 2008, observou-se a evolução do número de IES, quando no primeiro ano foram registradas 1.637 IES e, no ano de 2008, 2.252, verificando-se um crescimento de $37,57 \%$. Nesse sentido, Falcão (2007, p. 17) declara que o aumento "[...] de entrantes no segmento educacional advém não só do cenário de globalização do comércio e da economia, mas também do elevado aumento da demanda por esse tipo de serviço". Outro item de destaque revelado pelo Censo (2008) foram os números a favor do crescimento dos cursos de graduação. No ano de 2002, o Brasil contava com 14.399 cursos de graduação presencial e, em 2008, foram listados 24.719 , alta de $71,67 \%$ no período. No sentido de enaltecer a importância do setor de educação, Coelho (2007, p. 14) destaca que

[...] o sistema educacional ocupa uma posição fundamental na dinâmica dos processos de inovação tecnológica, de produção e difusão da ciência e da cultura, assim como desempenha um papel estratégico no desenvolvimento socioeconômico do país.

O mundo atual está marcado por grandes avanços científicos e tecnológicos e que a cada dia novas pesquisas são iniciadas objetivando melhorar a qualidade de vida humana ou para atender as necessidades criadas pelo próprio homem. Em todas essas iniciativas, conta-se de forma imperativa com o auxílio do computador. Hoje, já não é mais possível pensar em comunicação, saúde, educação, etc., sem a aplicação da informática. A computação está tão presente em nossa sociedade que sua importância é inquestionável (UNIVERSIDADE PASSO FUNDO, 2010). Diante de tal fato, a demanda por inovações ligadas à computação e informática é cada vez maior, sendo imprescindível a formação de bons profissionais na área de Ciência da Computação (UNIVERSIDADE SÃO PAULO, 2010). Torres (2010) relata que a área de informática engloba segmentos como computação e análise de sistemas, exige aprimoramento constante e que o mercado de trabalho está bem aquecido, com oferta de vagas de trabalho em empresas de produção de computadores, produção de software, grupos financeiros, centros de pesquisa e desenvolvimento, universidades, estabelecimentos de ensino e serviços públicos. (TORRES, 2010)

O curso de bacharelado em Ciência da Computação busca transmitir ao aluno uma base ampla de conhecimento, nos aspectos de teoria, modelagem $e$ desenvolvimento, em que a teoria se faz essencial para o entendimento da estrutura do computador (hardware e software) e dos métodos de organização, tratamento e comunicação da informação. A modelagem inclui métodos de projeto, análise, avaliação e verificação de sistemas, e o desenvolvimento trata de implementação e teste de sistemas de computação (UFMG, 2010). O desenvolvimento de sistemas e a construção de soluções computacionais para problemas da sociedade são contemplados pelos estudos do curso de Ciência da Computação (USP, 2010), abordando também, de maneira aprofundada, os conceitos e teorias da computação, proporcionando uma sólida formação em áreas como estruturas de informação, algoritmos, linguagens de programação, desenvolvimento e análise de sistemas.

Como parte fundamental deste estudo, deve-se frisar a apresentação do curso de Ciência da Computação no cenário brasileiro. No período de 2002 a 2008, as Sinopses Estatísticas da Educação Superior - Graduação (SEES/INEP) revelaram que o curso de graduação em Ciência da Computação obteve um crescimento de $20,96 \%$, sendo que o crescimento geral dos cursos de graduação sustentou o percentual de $71,67 \%$. Foram registrados 329 cursos de graduação em Ciência da Computação no ano de 2008. Do total dos cursos catalogados, tem-se que 95 deles estão distribuídos no estado de São Paulo e 32 em Minas Gerais, estados que aparecem na grade das IES e Cursos Cadastrados (e-Mec) como ocupantes dos $1^{\circ}$ e $2^{\circ}$ lugares nacionais para esse curso. Na $3^{a}$ colocação, estão os estados do Rio de Janeiro e Paraná, com 16 cursos registrados cada um. Estreitando a pesquisa para Minas Gerais, observa-se que das 32 IES que ministram o curso, seis estão em Belo Horizonte. Segundo o Censo 2008, o número de vagas ofertadas nos cursos de graduação das IES brasileiras foi de 2.985.137 e, desse total, Minas Gerais ficou com 268.447, sendo 46.587 dessas vagas para o curso de Ciência da Computação. O número de 
candidatos inscritos no Brasil foi de 5.534.689, com destaque de 591.317 inscrições em Minas, com referência de 82.712 em Ciência da Computação. Sobre o número de ingressos Minas contou com 149.854 ingressantes, dos quais 20.475 pertencem ao curso de Ciência da Computação.

\section{Modelos ou Estudos do Comportamento do Consumidor POR Cursos de Graduação}

Com o objetivo de verificar investigações empíricas anteriores sobre o tema, foram realizadas pesquisas bibliográficas sobre o comportamento do consumidor durante a escolha de cursos superiores, Instituições de Educação Superior (IES) e sobre a educação nas literaturas existentes, artigos científicos, trabalhos de pesquisa, bibliotecas de teses e dissertações das IES, análises teóricas e resenhas bibliográficas de grande representação e reconhecimento nacional, sendo elas publicadas nas principais revistas de administração do país. A pesquisa abrangeu os trabalhos apresentados no EnANPAD no período de 2005 a 2009 e nas revistas de administração: RAC, RAUSP e RAE nos anos de 2010, 2009, 2008, 2007, 2006 e 2005. Foram encontrados também artigos publicados no EnANPAD e nas bibliotecas virtuais de teses e dissertações das IES brasileiras.

O comportamento do consumidor com foco em cursos superiores pode ser ilustrado com o trabalho de Coelho (2007), que tem como objetivo geral identificar os atributos considerados importantes no processo de decisão de compra por cursos de pós-graduação lato sensu em Administração, para as IES de Belo Horizonte, no que se refere às etapas de reconhecimento de necessidades, busca de informações e avaliação de alternativas pré-compra (COELHO, 2007, p. 18). Os resultados foram obtidos a partir das etapas de levantamento das principais IES e dos cursos de pós-graduação lato sensu em Administração, em Belo Horizonte, e também dos atributos considerados importantes, classificados conforme sua tangibilidade, ligados ao processo de decisão por IES que oferecem esse curso. Como intangíveis foram apresentados seis tópicos: a) competitividade do egresso no mercado de trabalho, também dito como o valor do diploma no mercado, ou seja, a forma de o mercado decidir por contratar profissionais que estudaram na instituição de ensino A ou B; b) a análise da reputação das IES e cursos, relacionada com a comercialização do ensino e percepção do nome da instituição no mercado; c) o endosso social, pois mesmo pelas fontes de informações externas, observa-se a influência de parentes, amigos, professores como bons divulgadores das IES; d) o networking, visto como a possibilidade de manter contato com profissionais experientes no mercado, bem como uma forma de recolocação profissional e também como uma possibilidade de ampliação da rede de relacionamentos; e) a qualidade dos professores foi destacada a partir da manifestação dos entrevistados "[...] de terem docentes com experiência de mercado e/ou com experiência empresarial" (COELHO, 2007, p.92); e, por último, f) os critérios de seleção para a admissão nos cursos de pós-graduação lato sensu das IES resultou na observação dos candidatos por IES que possuem métodos mais exigentes, pois "[...] aparentemente IES mais rigorosas no processo de seleção dos alunos são vistas como de melhor qualidade, atraindo candidatos de nível mais elevado" (COELHO, 2007, p. 93). Para os atributos tangíveis, foram destacados sete quesitos, sendo eles: a localização da IES; a infraestrutura da IES, instalações físicas e equipamentos; os dias e horários das aulas; o valor das mensalidades; o tempo de duração do curso; o material didático e a estrutura curricular.

Já para o comportamento do consumidor na escolha por Instituições de Educação Superior, a pesquisa de Melo (2009, p. 48) abrangeu a coleta de dados primários com 17 alunos buscando levantar os "[...] estímulos que influenciavam de forma direta e/ ou indireta a satisfação dos alunos com relação aos serviços prestados pela Universidade". A dimensão social engloba

[...] alunos, atividades que geram socialização, cursos, palestras, empresas juniores, funcionários da biblioteca, funcionários da alimentação, funcionários da coordenação, funcionários da portaria e segurança, funcionários e coordenadores de centros, adequação da grade curricular e professores. (MELO, 2009, p. 49)

Nessa dimensão, alunos e professores receberam um maior número de variáveis, concluindo-se, assim, que esses personagens são os "[...] principais atores do 
ambiente educacional e que, por isso, geraram maior quantidade de estímulos na dimensão social dentro de uma universidade" (MELO, 2009, p.49). Para os professores, "[...] a pontualidade, acessibilidade, paciência com o aluno e grau de qualificação aparecem como aspectos de grande relevância para os alunos" (MELO, 2009, p.49). Já no caso dos alunos, a pesquisa revelou que eles

[...] apontam a falta de interesse dos colegas como principal fator de insatisfação. Situações como entra-e-sai de sala de aula, atender o celular na hora da aula $e$ ir para faculdade apenas porque o pai está pagando são percebidas como algo negativo. (MELO, 2009, p. 49)

Porém, como ponto positivo, "[...] os alunos acreditam que a convivência com os outros alunos na sala, monitoria, atividades acadêmicas e nos espaços de convivência estimulam a ida para a universidade". (MELO, 2009, p. 50)

Seguindo a linha de estudos baseada no processo de decisão do consumidor na avaliação de alternativas pré-compra, abrangendo suas etapas, fatores influenciadores, imagens que as pessoas possuem do objeto desejado, conceitos e aplicações dos itens segmentação, posicionamento e mapeamento perceptual, pode-se citar a pesquisa realizada por Martins (2006) "conhecer o processo decisório do prospects que prestaram o vestibular para o curso de administração em instituições de ensino superior da cidade de Belo Horizonte, estado de Minas Gerais". (MARTINS, 2006, p. 5). Já os objetivos secundários visavam "identificar os atributos da imagem atual que os prospectos possuem do curso avaliado e do posicionamento deste, além da identificação dos principais fatores usados para a escolha entre instituições concorrentes" (MARTINS, 2006, p. 5). Como parte dos resultados obtidos, tem-se que a qualidade de ensino foi o fator mais relevante para os vestibulandos e que

[...] ]os fatores reputação no mercado e competitividade do egresso no mercado aparecem empatados na segunda posição dentre os atributos relevantes para os alunos e tais atributos não apresentam diferenças significativas dentre os vestibulandos das IES pesquisadas. (MARTINS, 2006, p. 139)
Já para o fator localização, o resultado comprovou que os alunos não estão dispostos a se deslocarem por grandes distâncias para estudar. Dentro da comodidade de horários, a pesquisa revelou que os gestores das IES

[...] devem atribuir atenção especial aos horários em que irão disponibilizar seus cursos, de modo a permitir que alunos que trabalham ou têm outras atividades possam optar por estas instituições. (MARTINS, 2006, p. 139)

Para o quesito infraestrutura, alunos de diferentes IES destacaram percepções diversas sobre esse tema, demonstrando a necessidade de adoção de estratégias diferenciadas de infraestrutura pelos gestores. Um fator considerado menos importante para os alunos foi o endosso social, muitas vezes devido ao fato de os respondentes não aceitarem que outras pessoas possam influenciar sua escolha por uma IES. Percebe-se, na pesquisa, uma igualdade em relação aos quesitos atribuição de importância dos respondentes, qualidade de ensino, reputação, competitividade no mercado $e$ endosso social, o que demonstra certa comoditização dos serviços prestados pelas IES, fazendo com que esses atributos mereçam atenção especial pelos gestores das IES. Aliado a esses fatores, a comunicação e a prestação do serviço também poderiam receber novas estratégias mercadológicas, permitindo diferenciar as faculdades, identificando, por exemplo, diferenças na grade curricular, no conteúdo programático das disciplinas, na qualificação dos professores, dentre outras. (MARTINS, 2006, p. 140)

Marques (2008), no entanto, descreveu como proposta de pesquisa testar a validade de um modelo de lealdade do estudante com base na qualidade de relacionamento, com enfoque no marketing de relacionamento foi descrito por Marques (2008). Esse trabalho faz uma análise das relações entre qualidade percebida, comprometimento emocional e confiança, construtos formadores da qualidade do relacionamento e preditores da lealdade (MARQUES, 2008, p. 8). A pesquisa contou com 678 questionários considerados válidos e os resultados revelaram que no quesito qualidade dos serviços, os maiores níveis de percepção de qualidade estão entre os alunos entrantes, com menos de um ano de relacionamento com a universidade. Sobre a lealdade, o nível de confiança e o 
comprometimento emocional o resultado demonstrou que os alunos entrantes são mais leais, confiantes e comprometidos emocionalmente do que os alunos formandos. Para o comprometimento cognitivo e o comprometimento com os objetivos, obteve-se como resposta um comportamento bastante diferenciado entre os alunos formandos, que possuem mais de três anos de relacionamento com a IES, e os entrantes, com menos de um ano de relacionamento; notou-se, ainda, que com o passar dos anos, o aluno diminui seu nível de lealdade, comprometimento, confiança e até mesmo a percepção de qualidade, fazendo com que os gestores tomem conhecimento desse comportamento para atuarem de forma a minimizar os resultados dessa discrepância. (MARQUES, 2008, p. 77)

A pesquisa de Soares (2007) levantou questionamento sobre o crescimento avassalador do número de instituições de ensino superior de caráter privado e que por se tratar de um segmento altamente competitivo que as instituições de ensino superior estão à procura de sistemas de gestão mais eficientes, de forma a alcançar a vantagem competitiva na utilização de estratégias mais sólidas (SOARES, 2007, p. 7). Esse autor obteve por meio de uma survey com 260 questionários as seguintes conclusões: quanto aos antecedentes da satisfação, pode-se dizer que os custos de valor percebido, os benefícios funcionais, os benefícios pessoais e os benefícios de confiança impactam de forma positiva o comprometimento, ou seja,

[...] a confiança depositada no prestador de serviços, neste caso, a instituição de ensino superior, ainda que de forma 'tímida', é somada aos bons sentimentos e experiências recebidas no decorrer do curso. (SOARES, 2007, p. 102)

A satisfação, os custos de mudança, os benefícios pessoais e os benefícios de confiança foram classificados como os principais antecedentes do comprometimento, revelando que "[...] o aluno comprometido com sua instituição de ensino irá se esforçar ao máximo para concluir o curso, desfrutando de boas experiências de acordo com o modelo original" (SOARES, 2007, p. 102). O comprometimento é o antecedente de maior impacto sobre a lealdade, devido ao fato de a relação entre comprometimento $e$ a lealdade apresentar correlação com os custos de mudança sobre a lealdade; dessa forma, conclui-se
[...] que, no modelo testado, os alunos tendem a ser mais compromissados e leais a sua instituição de ensino, desconsiderando a troca ou mudança para instituição de ensino concorrente. Uma maior lealdade traduzir-se-ia possivelmente em resultados financeiros positivos. (SOARES, 2007, p. 102)

E, por último, a satisfação e o comprometimento são relevantes para os antecedentes boca a boca, pois significam que "[...] os alunos estão dispostos a falar coisas positivas sobre suas experiências para com sua instituição além de recomendá-la a outros amigos, colegas e pessoas do convívio social". (SOARES, 2007, p. 103)

O artigo de Fonseca (2009, p. 85) foi direcionado para entender quais fatores podem afetar o comportamento de compra dos jovens concluintes do ensino médio, aliado à importância do papel dos educadores, no auxílio para a tomada de decisão desses jovens, conciliando diferenças culturais com aspirações, desejos e necessidades. Um dos desafios encontrado é a falta de visão da instituição de que seus estudantes ou público-alvo são seus clientes, deixando de perceber que os "[...] clientes são, portanto, pessoas com necessidades e desejos que irão em busca de produtos e serviços que os satisfaçam, atendendo ou excedendo suas expectativas" (FONSECA, 2009, p. 90). Sobre esse aspecto, os alunos devem ser considerados como clientes de uma instituição de ensino,

[...] pois possuem a necessidade e o desejo de
buscarem uma qualificação e mais conheci-
mento, $e$ as universidades são as entidades que
oferecem os serviços e os meios para que estas
necessidades sejam alcançadas. (FONSECA,
2009, p. 90)

A cultura, nesse contexto, influencia o comportamento do consumidor, pois possibilita uma percepção de mundo, molda a conduta dos indivíduos e a percepção dos fatos e dos acontecimentos ao seu redor. Sobre os fatores influenciadores do comportamento de compra dos consumidores, Fonseca (2009) destaca o modelo descrito por Kotler (1998), no qual os consumidores reagem a diferentes estímulos de marketing relacionados ao produto, preço, ponto de venda e comunicação, somando-se a outros estímulos não ligados ao marketing, como fatores econômicos, 
tecnológicos, políticos e culturais. No caso do produto ofertado pela IES, Fonseca (2009) diz que o ensino é intangível, pois a qualidade só pode ser percebida após a aquisição do serviço, e que é importante considerar as experiências anteriores vivenciadas por familiares e amigos na hora da escolha pela instituição na qual o egresso do ensino médio realizará sua formação superior. Posto isso, tem-se que um

[...] serviço/educação/formação ofertado com qualidade terá um resultado positivo, amplificando, pois a cada pessoa satisfeita estará ligada uma corrente infinita de outras pessoas, facilitando o trabalho de comunicação e busca de novos clientes. (FONSECA, 2009, p. 93)

Como considerações finais desse artigo, Fonseca (2009, p. 95) considera que as instituições de ensino desempenham importante papel na busca por uma sociedade mais bem preparada, qualificada e competitiva, que os alunos devem estar conscientes da "[...] necessidade de serem cidadãos preparados para um mundo globalizado e desigual, onde somente os melhores preparados usufruirão das melhores oportunidades, das melhores colocações".

O trabalho de Falcão (2007) procurou relatar a diversidade no relacionamento e no desempenho de alunos de graduação em administração em uma Instituição de Ensino Superior privada. A apresentação dos resultados deu-se em dois momentos, um sustentado pela abordagem qualitativa objetivando identificar os aspectos comuns e distintos da amostra e os atributos que influenciam o desempenho dos entrevistados $e$ em segundo momento, visando verificar a frequência com que cada atributo da diversidade interfere no relacionamento e no desempenho do grupo pesquisado (FALCÃO, 2007, p. 45). Os resultados foram agrupados em 11 atributos, sendo eles: valores comuns do grupo (crenças duradouras), comportamentos compartilhados, faixa etária, formação educacional, renda, localização residencial, naturalidade, experiência profissional, preferência sexual, hábitos de lazer e condição econômica, para arcar com o curso (detentor ou não de bolsa de estudo). Ficou evidente que

[...] a maioria dos entrevistados considera determinante a existência de valores comuns entre estudantes, para a formação e aproximação de grupos em classe. (FALCÃO, 2007, p. 47)
Segundo manifestações dos alunos de graduação, a crença religiosa, seguida da afinidade de gostos, foi o núcleo de sentido que apresentou mais ocorrência, pois eles consideraram que a crença religiosa é capaz de influenciar o comportamento e convivência de estudantes dentro ou fora de sala. Para a faixa etária, conclui-se que ela

[...] interfere na formação de grupos em sala de aula, pois, de modo geral, os alunos se aproximam e relacionam-se com aqueles de mesma idade, ocasionando, conseqüentemente, distanciamento entre os estudantes de faixas etárias distintas. (FALCÃO, 2007, p. 55)

Quanto à formação educacional relatou-se que ela

[...] interfere diretamente no desempenho dos estudantes em classe, pois os alunos que estudaram no ensino privado apresentam melhor formação $e$ base do que os que vieram do ensino público e, conseqüentemente, mais facilidade de aprendizagem. (FALCÃO, 2007, p. 60)

Sobre a renda dos entrevistados tem-se

[...] segundo a metade da amostra que considera que a renda interfere no relacionamento dos estudantes, o seu impacto é especialmente negativo, pois distancia estudantes de condições socioeconômicas distintas, inclusive fora da Faculdade. (FALCÃO, 2007, p. 64)

A localização residencial foi considerada por apenas $3.57 \%$ dos entrevistados como fator de interferência no desempenho dos alunos, pois

[...] esse atributo impacta de forma positiva na performance dos estudantes, pois aqueles que residem distantes da Faculdade têm mais dedicação e comprometimento com os estudos, uma vez que valorizam mais a oportunidade de cursarem o ensino superior. (FALCÃO, 2007, p. 68)

Sobre a naturalidade, alguns relataram que a diferença cultural dificulta o desempenho dos estudantes que vêm de outras localidades, em função da diferença entre ensinos e quando esses alunos têm personalidade muito recatada ao ponto de se distanciarem naturalmente dos demais colegas de classe, devido a essa 
característica pessoal. A pesquisa revelou também que "[...] os estudantes oriundos de outras localidades são mais responsáveis, dedicados e comprometidos com os estudos e, conseqüentemente, apresentam desempenho diferenciado dos demais colegas de classe" (FALCÃO, 2007, p. 71). A maioria dos entrevistados relatou que a experiência profissional influencia de alguma forma a convivência dos estudantes, pois "[...] possibilita aos estudantes que trabalham dar dicas, conselhos e ensinamentos aos que não possuem experiência profissional [...]", eles relatam ainda que

[...] por intermédio do trabalho, os estudantes, além de adquirir a visão prática dos ensinamentos teóricos lecionados em classe, são capazes de desenvolver habilidade de saber lidar com pessoas diferentes, inclusive em momentos de adversidade. (FALCÃO, 2007, p. 75)

A preferência sexual não interfere no relacionamento dos alunos de graduação. Os hábitos de lazer podem ser considerados como uma forma de identificação de grupos, pois, as pessoas se

[...] identificam e aproximam-se daqueles que têm gostos iguais aos seus e apresentam personalidade ou estão passando por momentos de vidas semelhantes aos seus, fortalecendo, deste modo, a amizade e união das pessoas. (FALCÃO, 2007, p. 82)

E por último, metade dos entrevistados relatou que a condição do aluno bolsista influencia os resultados em classe,

[...] por acreditarem que os bolsistas se esforçam e estudam mais do que os não-bolsistas, tanto pelo medo de perder a bolsa de estudo quanto pela meta de aproveitamento mínimo de aprovação em $75 \%$ das disciplinas cursadas para a manutenção da bolsa de estudo. (FALCÃO, 2007, p. 85)

\section{Metodologia}

O processo metodológico refere-se aos procedimentos e técnicas que compõem determinado método, ou seja, um caminho para se alcançar o objetivo (RICHARDSON, 1999). Do ponto de vista de seus objetivos, trata-se de pesquisa descritiva, pois tem por finalidade descrever as características de determinada população ou fenômeno e estabelecer possíveis relações entre variáveis. Considerando a sua natureza, a pesquisa é a do tipo aplicada, pois seus resultados podem ser utilizados sob os aspectos gerenciais pelas organizações. Já quanto aos procedimentos técnicos, a pesquisa classifica-se como de levantamento (GIL, 1991). Sobre a forma de abordagem do problema, para responder aos objetivos propostos, a pesquisa é quantitativa. Foi realizado um diagnóstico quantitativo, com corte transversal, baseado em um levantamento do tipo survey ${ }^{1}$, avaliando a qualidade percebida, as atitudes $e$ as intenções comportamentais do grupo entrevistado.

Para o universo, amostra e período de estudo, a pesquisa utilizou como unidade de análise e unidade de observação o estudante de ensino superior do curso de Ciência da Computação de uma IES privada na cidade de Belo Horizonte - MG. Considerando a existência de 700 alunos matriculados no referido programa, foram coletados 208 questionários, através de coleta pessoal, no primeiro semestre de 2010, com alunos de diversos períodos do curso de graduação na área pretendida. Observa-se que 208 questionários levam a um erro amostral de 6\% com intervalo de confiança de 95\%.

A operacionalização do instrumento de pesquisa deste trabalho tomou como base a conceituação das etapas do processo decisório de compra descrito por Engel, Blackwell, Miniard (2000, 1995). Nesse sentido, esses autores descrevem os elementos e ações envolvidas em cada uma das etapas, o que fundamentou as questões e roteiro do questionário. De forma complementar, foram utilizados os referenciais de Sheth, Mittal e Newman (2008); Kotler (1998); Kotler e Keller (2006); Schiffman e Kanuk (2000); Solomon (2002); Churchill e Peter (2000), que coadunam com o modelo de processo decisório de Engel, Blackwell, Miniard (2000, 1995) e permitem detalhar os componentes de cada etapa, habilitando a definição das questões a serem incluídas no questionário desta pesquisa. Por outro lado, foram utilizados relatórios de pesquisas dos

\footnotetext{
1 A técnica de levantamento ou survey envolve entrevistas com base em uma amostra da população, por meio de questionários, que buscam levantar aspectos relacionados ao seu comportamento, às suas intenções, opiniões, atitudes etc. Podem-se coletar dados de forma pessoal, via telefone, por e-mail, por correio etc. A maioria das perguntas é de alternativa fixa ou predeterminada. As conclusões obtidas por meio de survey apresentam um maior caráter de generalização, por trabalharem com amostras grandes e representativas da população.
} 
trabalhos anteriores realizados pelo grupo de pesquisa do Mestrado da Universidade Fumec, Gonçalves Filho, Guerra e Moura (2004); Souki e Bernardes Neto (2007) e também artigo apresentado em seminário de administração Ribeiro, Prearo, Salles e Botelho de Souza (2010); e Fornell, et al. (1992), relacionados ao comportamento do consumidor de IES. Dentre eles:

\begin{tabular}{|c|c|c|}
\hline Escalas & FONTES & ITENS \\
\hline $\begin{array}{l}\text { Busca de } \\
\text { Informação }\end{array}$ & $\begin{array}{l}\text { Souki e Bernardes Neto (2007), } \\
\text { Gonçalves e Souki(2008) }\end{array}$ & 7 \\
\hline $\begin{array}{l}\text { Avaliação de } \\
\text { Alternativas } \\
\text { - Curso }\end{array}$ & $\begin{array}{l}\text { Souki e Bernardes Neto (2007), Ribeiro, } \\
\text { Prearo, Salles e Botelho de Souza } \\
\text { (2010); Gonçalves Filho, Guerra e Moura } \\
\text { (2004), Gonçalves e Souki(2008) }\end{array}$ & 22 \\
\hline $\begin{array}{l}\text { Avaliação de } \\
\text { Alternativas } \\
\text { - IES }\end{array}$ & $\begin{array}{l}\text { Souki e Bernardes Neto (2007), Ribeiro, } \\
\text { Prearo, Salles e Botelho de Souza } \\
\text { (2010); Gonçalves Filho, Guerra e Moura } \\
\text { (2004), Gonçalves e Souki(2008) }\end{array}$ & 6 \\
\hline $\begin{array}{l}\text { Atitudes com } \\
\text { relação à IES }\end{array}$ & $\begin{array}{l}\text { FORNELL, C., JOHSON, M.D., } \\
\text { ANDERSON, E.W., CHA, J., BRYANT, } \\
\text { B.E. (1992); Ribeiro, Prearo, Salles e } \\
\text { Botelho de Souza (2010); Gonçalves } \\
\text { Filho, Guerra e Moura (2004) }\end{array}$ & 9 \\
\hline $\begin{array}{l}\text { Preferência } \\
\text { de escolha de } \\
\text { IES (intenção } \\
\text { de compra) }\end{array}$ & $\begin{array}{l}\text { Souki e Bernardes Neto (2007), Ribeiro, } \\
\text { Prearo, Salles e Botelho de Souza } \\
\text { (2010); Gonçalves e Souki(2008) }\end{array}$ & 7 \\
\hline
\end{tabular}

Quadro 1: Operacionalização do instrumento de pesquisa Fonte: Dados de pesquisa

\section{AnÁlise dos Dados}

Considerando o objetivo de avaliar o comportamento do consumidor (alunos) de cursos de Ciência da Computação nas fases de busca de informação $e$ avaliação de alternativas, foi feita a divisão dos achados básicos relacionados a essas etapas. Previamente, apresentou-se o perfil dos participantes do estudo, bem como as análises preliminares e evidências de qualidade de mensuração. Em sequencia foi demonstrada a análise de exploração dos dados, de forma a lançar uma visão ampla dos resultados obtidos.

\subsection{Perfil dos Respondentes}

Ao todo foram coletados 208 questionários com alunos do primeiro ao oitavo períodos do curso de graduação na área pretendida. Em relação ao período, observa-se uma maior concentração de alunos nos períodos iniciais e no meio do curso, além de uma participação variada ao longo dos diversos períodos. Pode-se perceber, quanto ao sexo, a predominância de homens, refletindo o perfil típico dos alunos de cursos das áreas exatas e Ciências da Computação. A média de idade dos respondentes foi de 23 anos, observada por meio da predominância de alunos na faixa etária que antecede os 25 anos, evidenciando o perfil jovem dos egressos. Adicionalmente foi delineado o perfil ocupacional desses alunos, revelando que a maioria dos participantes do estudo, $68 \%$, já atua no mercado profissional, seja como empresário ou como empregado de empresa pública ou privada. A distribuição da amostra segundo a renda familiar mensal revelou faixas típicas da classe média, baixa e alta. Sobre a localização da IES, nota-se uma dispersão das proximidades entre casa e local de trabalho, na qual $87 \%$ dos respondentes afirmaram que a IES fica próxima de sua casa ou trabalho.

\subsection{Análise Exploratória dos DADOS}

Na etapa de análise exploratória dos dados foram avaliados requisitos e critérios de qualidade dos dados com vistas a subsidiar a antecipação e solução de problemas e vislumbrar que os dados do estudo tenham robustez e pertinência quanto ao tema (TABACHNICK; FIDEL, 2001). O tratamento dos dados ausentes foi feito, inicialmente pela exclusão de 40 questionários em branco, reduzindo a amostra inicial a 208 casos. A solução de dados ausentes aplicada foi a de uso de todas as informações disponíveis (pairwise deletion). A análise da significância dos testes de normalidade revelou desvios em todos os indicadores, apesar da amplitude dos desvios não ser grande o suficiente para ameaçar a aplicabilidade de métodos tradicionais de estimação.

Foi feita a análise tradicional de fidedignidade do instrumento de forma a identificar os indicadores que compunham as escalas de motivações para fazer ou procurar outro curso de graduação (Tabela 1). Inicialmente buscou-se conhecer a estrutura dimensional dessas escalas verificando quantos fatores latentes emergiam em cada grupo de variável. Para tanto, adotou-se a Análise Fatorial Exploratória, que permite agrupar e compreender os motivos de escolha 
de cursos superiores, obtendo fatores e dimensões subjacentes ao processo de escolha. A análise fatorial é um dos procedimentos mais populares de avaliação da dimensionalidade das escalas. (NETEMEYER et al., 2003)

Tabela 1: Análise Fatorial Exploratória - motivos de escolha

\begin{tabular}{|c|c|c|c|c|}
\hline \multirow[b]{2}{*}{ INDICADORES } & \multicolumn{4}{|c|}{ FATOR } \\
\hline & Profissionais & SociaIs & Pessoais & CONVENIÊNCIA \\
\hline 24) Pois permite obter um bom emprego & 0,933 & & & \\
\hline 25) Pois acredito que é uma carreira de futuro & 0,860 & & & \\
\hline 23) Pois paga bons salários & 0,634 & & & \\
\hline $\begin{array}{l}\text { 28) Porque pessoas conhecidas que } \\
\text { fizeram o curso recomendaram }\end{array}$ & & 0,856 & & \\
\hline 27) Porque parentes e amigos me recomendaram & & 0,766 & & \\
\hline 20) Pois gosto de Eletrônica/Eletricidade & & & 0,838 & \\
\hline 21) Pois gosto de Matemática e Ciências exatas & & & 0,770 & \\
\hline 29) Pois sempre gostei deste curso, seus assuntos e temas & & & 0,530 & \\
\hline $\begin{array}{l}\text { 26) Pois o curso que queria fazer é muito } \\
\text { difícil de passar no vestibular }\end{array}$ & & & & 0,824 \\
\hline 30) Pois é mais fácil passar no vestibular & & & & 0,680 \\
\hline Alpha de Cronbach & 0,762 & 0,767 & 0,557 & 0,619 \\
\hline Confiabilidade Composta & 0,856 & 0,794 & 0,762 & 0,725 \\
\hline \multicolumn{5}{|l|}{ CORRELAÇÕES ENTRE FATORES } \\
\hline Profissionais & 0,671 & 0,136 & 0,207 & $-0,105$ \\
\hline Sociais & 0,019 & 0,660 & 0,083 & 0,261 \\
\hline Pessoais & 0,043 & 0,007 & 0,525 & 0,093 \\
\hline Conveniência & 0,011 & 0,068 & 0,009 & 0,571 \\
\hline
\end{tabular}

Medida $\mathrm{KMO}=0,641$. Menor comunalidade 0,572. As cargas inferiores a 0,40 foram suprimidas por não serem significativas. Variância explicada $70 \%$. Na base da tabela se encontram-se as medidas de qualidade dos fatores. Na seção correlação encontram-se as correlações (acima da diagonal), a Variância Média Extraída (na diagonal principal em negrito) e as correlações ao quadrado (abaixo da diagonal).

Fonte: Dados da pesquisa

Foram encontrados basicamente quatro fatores para a escala de motivos de escolha do curso. As medidas de qualidade dessa análise mostraram condições aceitáveis para aplicação da AFE, bem como critérios de confiabilidade e validade. Somente o fator "motivos pessoais" obteve confiabilidade inferior a 0,600 , segundo Alpha de Cronbach, mas como os demais indícios de qualidade alcançaram o mínimo aceitável, considera-se tal escala válida.

Os resultados referentes às variáveis que buscam analisar o estágio de reconhecimento do problema, com atenção destacada para as opções de cursos disponíveis e as razões subjacentes da escolha do curso de Ciência da Computação foram relatados primeiramente a partir das medidas descritivas (média e desvio-padrão) em relação às crenças de quatro cursos da área de informática, Sistema da Informação, Engenharia da Computação, Ciência da Computação e Tecnólogos na área de Informática, notando-se entre os resultados da pesquisa importante destaque para o curso de Ciência da Computação (Tabela 2). 
Tabela 2: Estatísticas Descritivas das atitudes em relação ao curso

\begin{tabular}{|c|c|c|c|c|}
\hline & $\begin{array}{c}\text { A - Sistema } \\
\text { DE INFORMAÇÃo }\end{array}$ & $\begin{array}{l}\text { B - ENgenhaRia } \\
\text { DA Computação }\end{array}$ & $\begin{array}{l}\text { C - CiÊNCIA DA } \\
\text { ComputaÇÃo }\end{array}$ & $\begin{array}{c}\text { D - TeCNÓlogos NA ÁREA } \\
\text { DE INFORMÁtICA }\end{array}$ \\
\hline 6) Mercado & $7,67(1,45)$ & $7,62(1,68)$ & $8,62(1,31)$ & $6,74(1,82)$ \\
\hline 7) Salário & $6,85(1,83)$ & $7,59(1,96)$ & $7,62(2,02)$ & $5,95(1,83)$ \\
\hline 8) Dificuldade vestibular & $5,23(2,21)$ & $6,30(2,33)$ & $6,10(2,17)$ & $3,90(2,44)$ \\
\hline 9) Mensalidade & $8,26(1,58)$ & $8,87(1,55)$ & $9,18(1,16)$ & $6,93(2,18)$ \\
\hline 10) Afinidade & $7,28(1,96)$ & $7,31(2,27)$ & $8,97(1,09)$ & $6,57(2,49)$ \\
\hline 11) Dificuldade disciplinas & $7,11(1,60)$ & $8,41(1,78)$ & $8,51(1,23)$ & $6,15(1,78)$ \\
\hline
\end{tabular}

OBS: Os valores representam a média e o desvio padrão (entre parênteses). As médias apresentadas são obtidas somente dos casos com respostas completas. O objetivo é manter a base e a possibilidade de comparação estatística dos resultados. A maior diferença de médias para os casos completos (listwise) para todos os dados válidos (pairwise) é de 0,3 pontos.

Fonte: Dados da pesquisa

Em termos de avaliação dos cursos, nota-se um melhor posicionamento do curso de Ciência da Computação em praticamente todos os quesitos, exceto mensalidade (avaliado como mais caro) e dificuldade das disciplinas e vestibular. De forma geral, observa-se uma elevada aceitação de mercado e salários desse curso em relação às demais ofertas, mas também há um grande peso da dificuldade das disciplinas e preço da mensalidade como fatores que diminuem a relação custo benefício para os alunos. Quanto à avaliação dos fatores mais relevantes (por ordem) para a escolha do curso de Ciência da Computação foram obtidos os seguintes resultados: ter excelentes professores, possuir excelentes laboratórios e infraestrutura, possuir uma excelente estrutura (grade curricular), ter boa integração com o mercado e org./empresas empregadoras e ter mensalidades compatíveis com a qualidade oferecida. Ressalta-se que tais avaliações expressam a opinião dos alunos sem levar em conta seu processo afetivo de decisão, a interação que tais fatores sofrem ou as distorções originadas de respostas socialmente aceitas.

Na etapa de busca de informação foram avaliados os meios de comunicação utilizados pelos alunos atuais para obter informações sobre o curso, e como resultado a indicação de amigos, parentes e profissionais, bem como a internet se apresentaram como as principais formas utilizadas pelos alunos para buscarem informações sobre os cursos de Ciência da Computação (Tabela 3).
Tabela 3: Meios de informação para busca de informações sobre os cursos

\begin{tabular}{|c|c|c|}
\hline & $\%$ & FREQ. \\
\hline Mala direta (correio) & $0 \%$ & $(0)$ \\
\hline $\begin{array}{l}\text { Indicação da Diretoria do colégio onde eu } \\
\text { concluí o } 2^{\circ} \text { grau }\end{array}$ & $3 \%$ & (6) \\
\hline
\end{tabular}

Apresentação das instituições onde concluí $4 \% \quad$ (7) o $2^{\circ}$ grau

Visita do colégio onde concluí o $2^{\circ}$ grau à $5 \% \quad$ (9) instituição

Rádio $5 \% \quad(10)$

Indicação de professores do colégio onde $6 \% \quad$ (12) concluí o $2^{\circ}$ grau

Panfletos/folders $\quad 11 \%$

$\begin{array}{lll}\text { Outdoors } & 13 \% & \text { (25) }\end{array}$

Indicação de colegas de trabalho $\quad 15 \% \quad$ (28)

Indicação de ex-alunos que estudaram na $18 \%$ (35) instituição

Indicação de profissionais da área que eu $19 \%$ pretendo cursar

Indicação de alunos que estudam na insti- $26 \%$ tuição

\begin{tabular}{lcc} 
Televisão & $26 \%$ & $(49)$ \\
Na própria instituição & $30 \%$ & $(57)$ \\
\hline Indicação de parentes & $30 \%$ & $(58)$ \\
Indicação de amigos & $45 \%$ & $(87)$ \\
\hline Internet & $48 \%$
\end{tabular}

OBS: \% é o percentual de respostas. FREQ > é q frequência de respostas na amostra.

Fonte: Dados da pesquisa 
Além do levantamento das fontes de informação usadas pelos alunos, foram identificadas as alternativas de cursos que os alunos buscariam caso decidissem fazer novamente o vestibular e o resultado demonstrou que $46 \%$ dos alunos atuais não se arrependeram da escolha de curso e continuariam no mesmo curso, mas um número representativo de respondentes preferiu outras opções de cursos, especialmente as engenharias. Nota-se que os motivos principais remetem a questões profissionais e ao fato de se gostar de computadores. Foram questionados também os motivos que levariam o aluno a procurar outro curso e o resultado demonstrou que o principal motivo seria o investimento, percebido como muito alto tanto financeiramente quanto em questão de tempo.

Os resultados referentes ao processo de decisão de compra e avaliação de alternativas foram observados a partir das medidas descritivas (média e desvio padrão) em relação às crenças de cinco IES privadas que ofertam o curso de Ciência da Computação (Tabela 4).

Tabela 4: Estatísticas Descritivas das atitudes em relação às instituições

\begin{tabular}{|c|c|c|c|c|c|}
\hline VARIÁVEIS & IES A & IES B & IES C & IES D & IES E \\
\hline 40) Preço justo & $\begin{array}{c}\mathrm{R} \$ 669 \\
(125)\end{array}$ & $\begin{array}{c}\mathrm{R} \$ 492 \\
(143)\end{array}$ & $\begin{array}{c}\mathrm{R} \$ 638 \\
(130)\end{array}$ & $\begin{array}{c}\mathrm{R} \$ 528 \\
(142)\end{array}$ & $\begin{array}{c}\mathrm{R} \$ 544 \\
(157)\end{array}$ \\
\hline $\begin{array}{l}\text { 42) Qualidade de } \\
\text { ensino, professores } \\
\text { e infraestrutura }\end{array}$ & $\begin{array}{c}8,08 \\
(1,46)\end{array}$ & $\begin{array}{l}5,18 \\
(2,06)\end{array}$ & $\begin{array}{c}7,97 \\
(1,39)\end{array}$ & $\begin{array}{c}5,64 \\
(2,02)\end{array}$ & $\begin{array}{c}6,33 \\
(2,21)\end{array}$ \\
\hline $\begin{array}{l}\text { 43) Localização } \\
\text { e acesso }\end{array}$ & $\begin{array}{c}6,18 \\
(2,83)\end{array}$ & $\begin{array}{c}6,66 \\
(2,18)\end{array}$ & $\begin{array}{c}8,02 \\
(2,13)\end{array}$ & $\begin{array}{c}6,33 \\
(2,13)\end{array}$ & $\begin{array}{c}5,87 \\
(2,17)\end{array}$ \\
\hline $\begin{array}{l}\text { 44) Valor do diploma } \\
\text { no mercado, marca } \\
\text { e reputação }\end{array}$ & $\begin{array}{c}9,02 \\
(1,01)\end{array}$ & $\begin{array}{c}5,03 \\
(2,18)\end{array}$ & $\begin{array}{c}7,84 \\
(1,39)\end{array}$ & $\begin{array}{c}5,56 \\
(1,72)\end{array}$ & $\begin{array}{c}6,30 \\
(2,01)\end{array}$ \\
\hline $\begin{array}{l}\text { 45) Valor da } \\
\text { mensalidade }\end{array}$ & $\begin{array}{c}4,96 \\
(3,43)\end{array}$ & $\begin{array}{r}5,86 \\
(2,33)\end{array}$ & $\begin{array}{c}4,29 \\
(3,73)\end{array}$ & $\begin{array}{c}5,66 \\
(2,37)\end{array}$ & $\begin{array}{c}5,60 \\
(2,65)\end{array}$ \\
\hline $\begin{array}{l}\text { 46) Ensino com } \\
\text { enfoque prático e } \\
\text { aplicado ao mercado }\end{array}$ & $\begin{array}{c}7,09 \\
(2,16)\end{array}$ & $\begin{array}{c}5,89 \\
(2,02)\end{array}$ & $\begin{array}{c}7,18 \\
(2,05)\end{array}$ & $\begin{array}{c}6,56 \\
(1,81)\end{array}$ & $\begin{array}{c}6,17 \\
(2,25)\end{array}$ \\
\hline $\begin{array}{l}\text { 47) Integração } \\
\text { com o mercado de } \\
\text { trabalho e empresas }\end{array}$ & $\begin{array}{c}7,58 \\
(2,11)\end{array}$ & $\begin{array}{c}5,17 \\
(2,25)\end{array}$ & $\begin{array}{c}7,12 \\
(2,08)\end{array}$ & $\begin{array}{c}5,70 \\
(2,34)\end{array}$ & $\begin{array}{c}5,93 \\
(2,33)\end{array}$ \\
\hline 48) Preferência & $\begin{array}{c}7,60 \\
(2,21)\end{array}$ & $\begin{array}{c}2,78 \\
(2,73)\end{array}$ & $\begin{array}{l}7,97 \\
(2,3)\end{array}$ & $\begin{array}{c}3,47 \\
(2,82)\end{array}$ & $\begin{array}{c}4,12 \\
(2,91)\end{array}$ \\
\hline
\end{tabular}

OBS os valores representam a média e desvio padrão (entre parênteses). As Médias apresentadas são obtidas dos casos com respostas válidas.

Fonte: Dados da pesquisa
Pensando em um modelo de regressão múltipla, o mais apropriado, neste estudo ${ }^{2}$, é organizar os dados de modo que cada linha represente uma observação da variável dependente seguida pelas variáveis independentes e prosseguir com a análise de mínimos quadrados ordinários. Com base nesse procedimento, avançou-se a análise para o modelo de regressão geral, conforme Tabela 5, com o objetivo de avaliar o processo decisório de escolha de IES, cuja variável dependente foi a intenção de escolha por uma determinada IES. Nesse sentido, foram observadas as variáveis de maior impacto no processo de escolha da IES.

Tabela 5: Modelos de Regressão Global

\begin{tabular}{|c|c|c|c|c|c|}
\hline OPÇõES & PESOS & ERRO & BETA & EST T & SIG. \\
\hline (CONSTANTE) & $-0,564$ & 0,381 & & $-1,480$ & 0,140 \\
\hline $\begin{array}{l}\text { 42) Qualidade de } \\
\text { ensino, professores } \\
\text { e infraestrutura }\end{array}$ & 0,344 & 0,127 & 0,177 & 2,704 & 0,007 \\
\hline $\begin{array}{l}\text { 44) Valor do } \\
\text { diploma no } \\
\text { mercado, marca } \\
\text { e reputação }\end{array}$ & 0,533 & 0,120 & 0,293 & 4,431 & 0,000 \\
\hline $\begin{array}{l}\text { 45) Valor da } \\
\text { mensalidade }\end{array}$ & $-0,035$ & 0,073 & $-0,018$ & $-0,479$ & 0,632 \\
\hline $\begin{array}{l}\text { 46) Ensino com } \\
\text { enfoque prático e } \\
\text { aplicado ao mercado }\end{array}$ & 0,179 & 0,131 & 0,075 & 1,374 & 0,170 \\
\hline $\begin{array}{l}\text { 47) Integração } \\
\text { com o mercado de } \\
\text { trabalho e empresas }\end{array}$ & 0,251 & 0,118 & 0,128 & 2,129 & 0,034 \\
\hline $\begin{array}{l}\text { 43) Localização } \\
\text { e acesso }\end{array}$ & 0,185 & 0,052 & 0,135 & 3,572 & 0,000 \\
\hline
\end{tabular}

OBS: Os pesos correspondem aos pesos beta estimados na relação linear; o erro é o erro padrão da estimativa; o valor beta corresponde aos pesos padronizados; o valor t é a razão t da estimativa por seu erro padrão; a significância é a significância do teste $t$ bicaudal. O erro dos parâmetros nos modelos por marca não está segundo procedimento de Jonhston $e$ Di ${ }^{N}$ Nardo (1997) porque isso implicaria um número de graus de liberdade negativo nesses modelos.

Fonte: Dados de pesquisa

Quando se observam os modelos de regressão, nota-se que, no momento de decisão de compra, o valor do diploma no mercado, qualidade de ensino, localização e integração com empresas são os fatores mais relevantes para o aluno. $\mathrm{O}$ valor da mensalidade

2 Já que neste estudo há somente uma variável dependente e um conjunto de variáveis independentes e cada um deles é mensurado com somente um indicador. 
e o enfoque prático do ensino não foram significativos no modelo.

Os resultados da avaliação dos alunos no pós-compra, com a IES pesquisada, revelaram que, apesar de uma satisfação "moderada", o valor percebido é bastante reduzido dentre os alunos, e que os indicadores de lealdade são baixos e não expressam uma ligação forte entre os alunos e a instituição. A aplicação da técnica foi feita por meio do procedimento de Path Analysis sugerido por Joreskog e Sorbom (1989), no qual cada variável latente é representada por somente um indicador observado. Assim, as variáveis dependentes da seção de atitudes e intenções comportamentais podem ser avaliadas, bastando para isso fixar seu erro de mensuração em patamares pré-fixados (nesse caso 0 ). Já o construto qualidade foi avaliado como um fator reflexivo em seu formato tradicional, sendo que as dimensões de qualidade foram compostas pelas questões Q43 a Q47, considerando somente as avaliações da instituição pesquisada (as perguntas dos concorrentes não foram consideradas para esse fim).

\subsection{Modelo Hipotético: impacto da satisfação nas intenções comportamentais de alunos}

A estrutura de teste se baseou no modelo de pesquisa utilizado para medir a satisfação geral dos alunos da instituição pesquisada. Após o teste do modelo em seu formato tradicional, avançou-se para a exclusão de caminhos não significativos e para a inclusão de relações não previamente consideradas, por meio da análise dos índices de modificação (KLINE, 1998). O objetivo era adotar uma abordagem exploratória (HAIR et al., 1998), mas de perspicaz utilidade para desvelar o modelo de comportamento pós-compra (atitudes e intenções comportamentais) dos alunos do curso pesquisado, aprofundando-se sobremaneira nas especificidades desses alunos. A partir da reformulação de uma estrutura genérica, obteve-se um modelo específico para esse grupo, conforme resultados delimitados na Figura 1.

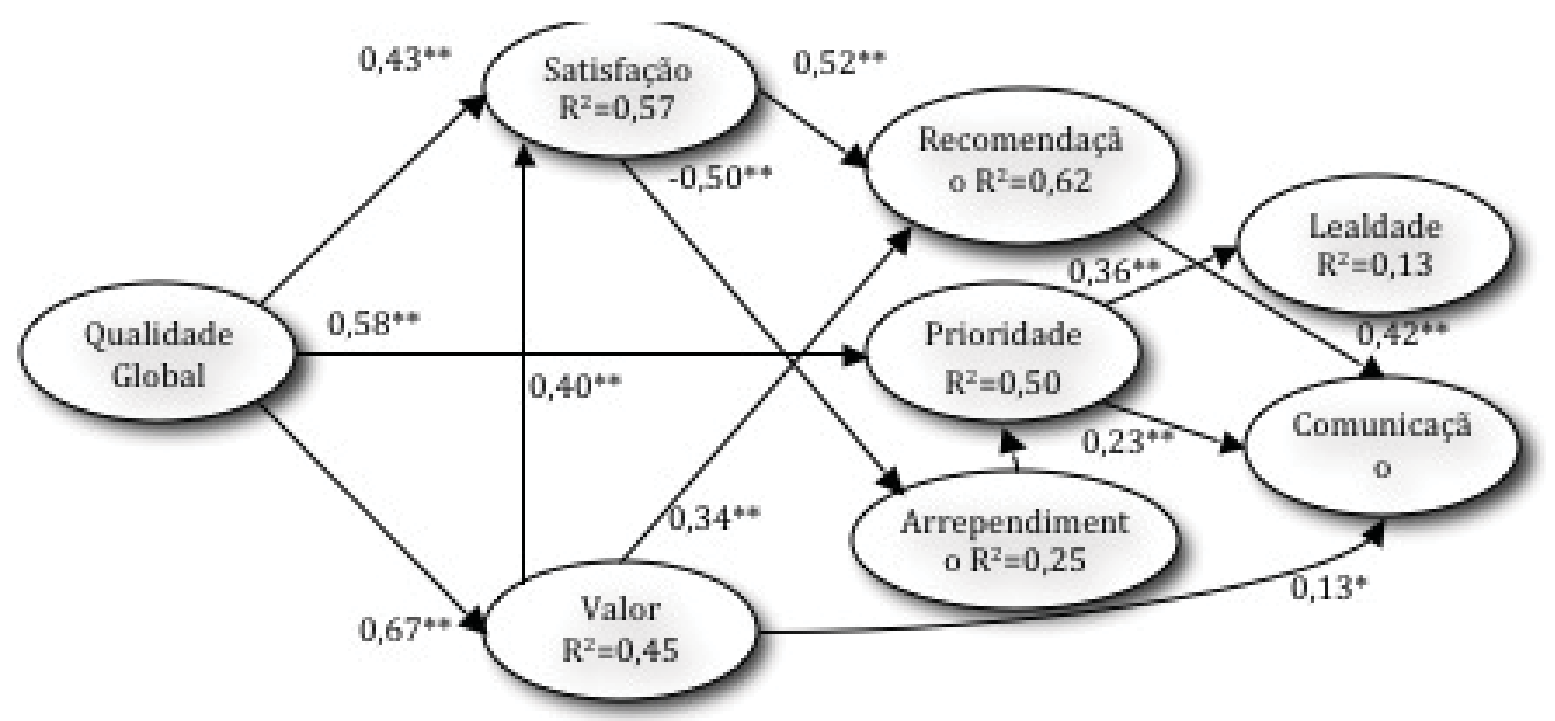

Observações: Os valores apresentados junto às setas indicam o valor das cargas padronizadas. ** indica a significância da carga ao nível de 0,1\% ( $\mathrm{p}<0,001$ ); * indica a significância da carga ao nível de $5 \%(p<0,05)$. O Valor $\mathrm{R}^{2}$ indica o percentual de variância explicada dos construtos endógenos.

Notas: PAD. é a estimativa padronizada. Ajuste do modelo: Qui-quadrado=175,829 ( $p<0,01)$. Ajuste Absoluto (CMIN/DF=2,93; GFI=0,881). Ajuste Incremental (AGFI=0,820; NFI=0,853; RFI=0,809; IFI=0,898; TLI=0,866; CFI=0,897). Ajuste Relativo (PGFI=0,581; PNFI=0,656; PCFI=0,69).

Figura 1: Modelo hipotético de pesquisa

Fonte: Dados da pesquisa 
As hipóteses do modelo tiveram origem em Fornell et al. (1992), hipóteses que relacionam satisfação, comunicação/boca a boca positivo, lealdade, qualidade e valor percebido e de Gonçalves, Souki e Gomes (2008), hipóteses que relacionam prioridade, recomendação e arrependimento.

Verificando os resultados do modelo, é possível observar os representativos impactos da qualidade e o valor na satisfação, o que corrobora com estudos anterior de Fornell et al. (1992). Por outro lado, verifica-se o relevante impacto negativo da satisfação no arrependimento, sugerindo importantes implicações gerenciais. Já no que se refere à prioridade (intenção de dar preferência a IES em próximo curso), é possivel observar os significativos impactos da qualidade percebida e do arrependimento (este último mediando a relação ente satisfação e prioridade de escolha). Por fim, apresentam-se os impactos significativos da recomendação, valor e prioridade no boca a boca/ comunicação positiva, bem como da prioridade de escolha na lealdade.

Em uma análise inicial do modelo sob a ótica dos antecedentes da satisfação, 'e possível observar que a qualidade percebida $(\beta=0,43)$ e o valor $(\beta=0,40)$ são os construtos que têm maior impacto sobre a satisfação na amostra estudada. Tal constatação concorda com os resultados de Fornell et al. (1996) que comprovou empiricamente ser a satisfação mais orientada à qualidade do que valor ou expectativas. Nesse sentido, organizações deste ramo de serviços devem investir seus esforços primariamente em qualidade e valor para obterem lealdade e satisfação de seus egressos.

As variáveis atitudinais foram previstas de forma expressiva A comunicação positiva realizada pelos alunos também apresentou um índice elevado de predição. Não obstante, a lealdade (54 - Estou propenso a me matricular em outros cursos oferecidos pela IES C) foi baixa, o que se pode originar da indisposição dos alunos de buscar a continuidade de seus estudos, independentemente da instituição de ensino, isto é, parte considerável dos alunos não espera continuar seus estudos após a finalização do curso atual. Por outro lado, a comunicação positiva aparece como tendência comportamental altamente ditada pelas demais atitudes, mostrando a importância de desenvolver a qualidade do curso a fim de se perpetuar uma imagem positiva da instituição. Observa-se o papel central da qualidade percebida e do valor no modelo testado, sugerindo ser esse construto de grande relevância para gestão de relacionamento e comportamento de fidelidade de alunos e egressos.

Já no que se refere ao impacto da satisfação sobre a recomendação, o $\beta$ de 0,52 , demonstra-se a importância da satisfação para a recomendação. Essa medição está em sintonia com grande parte das pesquisas realizadas, tais como a de Veiga (2000), e demonstra que a satisfação continua sendo uma grande arma para obtenção da lealdade. Por outro lado, observa-se que a qualidade global apresenta impacto positivo com a prioridade $(\beta=0,58)$. Já no que se refere ao valor, ele tem impacto relevante proveniente da qualidade $(\beta=0,67)$.

\section{Considerações Finais}

Conhecer o comportamento do consumidor, segundo Solomon (2002), envolve um processo de tomada de decisão, aquisição e consumo de bens $e$ serviços de modo a satisfazer as necessidades $e$ os desejos dos clientes/consumidores. Este trabalho foi elaborado a partir do conceito do comportamento do consumidor, da importância da Ciência da Computação no cenário global e do papel fundamental que as Instituições de Educação Superior desempenham na formação profissional e até mesmo pessoal do cidadão.

O objetivo principal desta pesquisa foi avaliar o comportamento do consumidor (alunos) de cursos de Ciência da Computação nas fases de busca de informação e avaliação de alternativas. Já os objetivos específicos visavam identificar as principais fontes de informações para escolha de instituição de ensino superior na avaliação de alunos de Cursos de Ciência da Computação e verificar os elementos de maior relevância na escolha dos cursos (características dos cursos e instituições de ensino superior) na fase de avaliação de alternativas de escolha por alunos de Cursos de Ciência da Computação.

Para o processo de busca de informação, a pesquisa realizada com os alunos do curso de Ciência da Computação revelou as principais fontes de busca utilizadas para a obtenção das informações necessárias sobre o curso pretendido. Com base na Tabela 3 , é possível observar que a internet foi considerada 
o meio mais utilizado pelos alunos, com $48 \%$ dos respondentes destacaram suas consultas por meio dessa ferramenta. Em seguida, com os melhores percentuais tem-se a indicação de amigos, com $45 \%$, indicação de parentes e na própria instituição $30 \%$, indicação de alunos que estudaram na instituição e a informação através da televisão sustentaram $26 \%$ das respostas coletadas. Já a indicação de profissionais da área do curso que o aluno pretendia cursar ficou com 19 \%. Para a indicação de ex-alunos que estudaram na instituição, obtiveram-se $18 \%$ dos entrevistados. Abaixo dos $18 \%$, tem-se a busca de informação por meio de indicação de colegas de trabalho, com 15\%; as informações contidas em outdoors, com $13 \%$; a divulgação através de panfletos e folders, com $11 \%$; a indicação de professores do colégio de conclusão do $2^{\circ}$ grau, com $6 \%$; propagandas em rádio, $5 \%$; $4 \%$ dos respondentes indicaram que buscaram informação na IES quando em visita organizada pelo colégio onde concluiu o $2^{\circ}$ grau, com $5 \%$; $4 \%$ dos respondentes buscaram informação através da apresentação das instituições e $3 \%$ indicação da Diretoria do colégio de conclusão do $2^{\circ}$ grau. Não se obteve resposta para a busca de informação por meio de mala direta.

Já para a avaliação das alternativas quanto à profissão, ou seja, os motivos de escolha pelo curso, encontra-se a aplicação de uma análise fatorial exploratória que revelou, conforme a Tabela 1 , que os fatores que compõem a escolha do curso são os profissionais, sociais, pessoais e de conveniência. Além dessa identificação, a Tabela 1 também demonstrou o grau de importância entre os fatores.

No que se refere ao fator profissional, cita-se que os principais motivos de escolha pelo curso de Ciência da Computação estão ligados à possibilidade de obter bom emprego, por se acreditar ser uma carreira do futuro e pelos bons salários que o profissional pode receber por seu trabalho. Já o fator social recebeu como indicador de escolha do curso a boa aceitação e recomendação de pessoas conhecidas, amigos e parentes que fizeram o curso. Os motivos que envolvem o fator pessoal podem ser descritos através da afinidade do aluno pela Eletrônica/Eletricidade, Matemática e Ciências Exatas e por sempre ter gostado do curso e de seus assuntos e temas. $\mathrm{O}$ fator conveniência revelou que passar no vestibular do curso que o aluno queria fazer era muito difícil sendo mais fácil passar no vestibular para Ciência da Computação.

Foram levantadas também as atitudes em relação ao mercado, salário, dificuldade no vestibular, valor da mensalidade, afinidade com o curso e dificuldade das disciplinas relacionando o curso de Ciência da Computação e os afins na área da computação ou informática, sendo eles Sistema da Informação, Engenharia da Computação, e Tecnólogos na área de Informática (Tabela 2). Os resultados revelaram importante destaque para o curso de Ciência da Computação, porém a mensalidade foi considerada a mais cara entre eles e também a dificuldade das disciplinas.

Em relação à avaliação das alternativas para escolha da Instituição de Educação Superior, foram consideradas as características que a IES possui para atrair o aluno, obtiveram-se como resultado, através da regressão beta -1 a +1 , os seguintes dados de pesquisa: a Tabela 5 mostra uma regressão das variáveis que pesam na escolha da IES. Conforme o índice de regressão beta padronizado de 0,293, a variável que mais pesa na escolha de uma IES é o valor do seu diploma no mercado, marca e reputação, seguido pela qualidade de ensino, professores e infraestrutura, com beta padronizado de 0,177 , integração da IES com o mercado de trabalho e empresas com 0,128 e por último com beta de 0,135 a localização e acesso da IES. Fazendo um levantamento comparativo de várias IES, verifica-se, conforme Tabela 4, as estatísticas descritivas das atitudes em relação às IES, com atribuições de médias diferentes para as IES-A, IES-B, IES-C, IES-D e IES-F.

Os resultados encontrados na pesquisa demonstram a necessidade de os gestores da Instituição de Educação Superior pesquisada entenderem o comportamento de seus alunos, para que, munidos desse entendimento, possam agir eficazmente na disputa por seu aluno, de forma a garantir sua lealdade à IES, a confiança para indicações a parentes e amigos e a conquistar novos alunos.

Analisando a busca de informações, os gestores devem investir na descrição do curso pela internet, pois $48 \%$ dos entrevistados apontaram essa ferramenta como principal meio de busca de informação para o curso. Faz-se importante disponibilizar a grade do curso, o objetivo principal, o currículo dos professores, o contato direto com os coordenadores do curso, bem como seu currículo, opções de turnos, parcerias com 
empresas para estágios, acervo da biblioteca com autores renomados e publicações de destaque no mercado, laboratórios modernos, dentre outros. Em um segundo instante, os gestores devem garantir a prestação de serviço de qualidade de forma a manter o grau de satisfação do egresso e garantir a sua lealdade e credibilidade para que ele seja um condutor eficiente de divulgação boca a boca, pois $45 \%$ e $30 \%$ dos entrevistados, respectivamente, relataram que buscaram informações através de indicação de amigos e parentes.

Para a avaliação de alternativa, os gestores devem direcionar esforços na construção da marca no mercado. A IES precisa trabalhar sua marca para que ela transpareça confiança e credibilidade, de forma a garantir reconhecimento do seu diploma no mercado. O curso também deve ser desenvolvido para reter maior atenção dos candidatos de forma que eles possam tomar a decisão em fazer esse curso como sua primeira opção e para que não haja a migração para outros cursos. Dessa forma, faz-se importante prover a manutenção de professores bons e experientes, material impresso adequado, grade atrativa e de qualidade. A comunicação entre IES e o curso deve estar sempre alinhada de forma que o produto, nesse caso, o curso de Ciência da Computação, seja um argumento de grande peso na decisão do candidato por estudar nessa determinada IES.

Como elemento que agregue valor para a escolha do curso nessa determinada IES, pode-se propor uma pesquisa que vise a observar as emoções que o curso desperta em seus alunos e de que forma ela pode afetar na satisfação desse egresso no curso. De posse desse resultado, a IES pode investir nos estímulos que gerem essa satisfação, aliando a influência dos estímulos ambientais e das reações emocionais que elas proporcionam. Tal estudo pode revelar uma maneira de garantir a retenção e a lealdade do aluno, $e$, de certa forma, o reconhecimento da marca da IES no mercado, devido à propaganda positiva feita pelos alunos satisfeitos.

A pesquisa sobre o comportamento do consumidor por cursos superiores ajuda a gerar um conhecimento maior sobre esses cursos. Em relação a este trabalho, pode-se dizer que ele é único por tratar do conhecimento específico da Ciência da Computação. Apesar de ser um curso com vários alunos e de grande importância nos setores econômico, social, científico e pessoal, não foram encontrados estudos anteriores sobre o tema, podendo explicitar a geração de uma necessidade de formação mais sólida de conhecimento nessa área.

Conforme observado, esta pesquisa possui uma única amostra realizada com alunos do curso de Ciência da Computação de uma só Instituição de Educação Superior privada na cidade de Belo Horizonte - MG, o que limita a capacidade de generalização do estudo. Uma amostra maior poderia revelar outros benefícios a partir do modelo de pesquisa aqui adotado. Outro trabalho poderia ser feito no sentido de pesquisar alunos dos cursos correlatos ao de Ciência da Computação para avaliar o motivo da migração do aluno de Ciência da Computação para outros cursos e também pesquisar alunos de Ciência da Computação de outras IES de modo a gerar um perfil mais diversificado do aluno.

Sugere-se replicar este estudo nacionalmente, abrangendo outras IES, criando um modelo de comportamento do consumidor para outros cursos da área tecnológica ou das exatas, e não somente para o de Ciência da Computação. Trabalhar também com outras fases do comportamento do consumidor, como a de reconhecimento da necessidade ou a de processo de compra, e realizar um estudo mais detalhado dos processos pós-compra e lealdade do egresso.

\section{REFERÊNCIAS}

\section{ALECRIM, Emerson. Ciência da computação,} engenharia da computação ou sistema de informação? InfoWester, 13 de outubro de 2007. Disponível em: <http://www.infowester.com/col290804. php>. Acesso em: 30 mar. 2010.

BLOCK, Carl E.; ROERING, Kenneth J. Essentials of consumer behavior. Chicago: Dryden-Press, 1976. In: TERCI, Suzie. Você realmente sabe o que é comportamento do consumidor? Iniciação Científica,

Cesumar, Maringá, v. 3, n. 2, p. 91-103, ago./dez., 2001. Disponível em: <http://www.cesumar.br/pesquisa/ periodicos/index.php/iccesumar/article/view/42/5>. Acesso em: 17 jun. 2010. 
BRITO, Maria do S. T. Qualidade e profissionalização: o compromisso do ensino técnico e superior. In: QUELUZ, Ana Gracinda (Org). Educação sem fronteiras: em discussão o ensino superior. São Paulo: Pioneira, 1996. p. 17-21.

CARPINELLI, Carmem S. A. Avaliação globalizadora: um desafio para a universidade. In: QUELUZ, Ana Gracinda (Org.). Educação sem fronteiras: em discussão o ensino superior. São Paulo: Pioneira, 1996. p. 23-30.

CENSO da Educação Superior. Ministério da Educação - Instituto Nacional de Estudos e Pesquisas Educacionais Anísio Teixeira. Censo da Educação Superior de 2008 (dados preliminares) resumo técnico. Disponível em: <http://www.inep.gov.br/superior/ censosuperior/relatorio_tecnico.htm $>$. Acesso em: 17 mar. 2010.

CHURCHILL, Gilbert A.; PETER, J. Paul. Marketing: criando valor para o cliente. São Paulo: Saraiva, 2000.

\section{COELHO, Renata R. S. Comportamento do}

consumidor: um estudo exploratório sobre cursos de pós-graduação lato sensu em administração. 2007. 114 f. Dissertação (Mestrado da Faculdade de Ciências Empresariais - FACE) - Universidade Fumec, Belo Horizonte, 2007. Disponível em: < http://www.face.fumec. $\mathrm{br} / \mathrm{cursos} / \mathrm{mestrado} /$ dissertacoes/completa/renata_ribeiro_ salles_coelho.pdf $>$. Acesso em: 7 jun. 2010.

CRONBACH, Lee J. Coeficient Alpha and the internal structure of tests. Psychometrika, Illinois, v. 16, p. 297 334, 1951.

DUBOIS, B. Compreender o consumidor. 2. ed. Lisboa: Publicações Dom Quixote, 1991.

ENGEL, James F; BLACKWELL, Roger D; MINIARD, Paul. Comportamento do consumidor. Rio de janeiro: LTC, 2000.

ENGEL, James F; et al. Comportamento do consumidor. 8. ed. Rio de Janeiro: Editora JC, 1995.
FALCÃO, Bruno de Medeiros. Diversidade no relacionamento e no desempenho de alunos de graduação em administração. 2007. 99 f. Dissertação (Mestrado da Faculdade de Ciências Empresariais FACE) - Universidade Fumec, Belo Horizonte, 2007. Disponível em: <http://www.face.fumec.br/cursos/ mestrado/dissertacoes/completa/bruno_medeiros_falcao_ daniel.pdf > . Acesso em: 8 jun. 2010.

FONSECA, Claudia Liane Ávila da. Comportamento do consumidor, cultura e educação: a busca pela formação superior. Anuário de Produção Acadêmica Docente, Anhanguera, v. 3, n. 4, p.83-96, 2009. Disponível em: $<$ http://sare.unianhanguera.edu.br/index.php/anudo/ article/viewFile/1306/717 > . Acesso em: 12 jul. 2010.

FORNELL, C. A National Customer Satisfaction Barometer: the Swedish Experience. Journal of Marketing, Chicago, v. 56 (january), p. 6-21, 1992.

FORNELL, C. et al.; American Customer Satisfaction Index: Nature, Purpose and Findings. Journal of Marketing, New Yoork: AMA, v. 60, p. 7-18, Oct. 1996.

GAVALDON, Luiza L. A qualidade do ensino na visão do aluno. In: QUELUZ, Ana Gracinda (Org.). Educação sem fronteiras: em discussão o ensino superior. São Paulo: Pioneira, 1996. p. 7-16.

GIL, Antonio Carlos. Métodos e técnicas de pesquisa social. São Paulo: Atlas, 1991.

GONÇALVES FILHO, C.; GUERRA, Renata Souza; MOURA, Alexandre Inácio. Mensuração de satisfação, qualidade, lealdade, valor e expectativa em instituições de ensino superior: um estudo do modelo ACSI através de Equações Estruturais. Gestão. Org. Revista Eletrônica de Gestão Organizacional, Recife, v. 2, n. 1, p. 1-14, 2004.

GONÇALVES FILHO, C.; GUERRRA, Renata Souza; MOURA, Alexandre Inácio. Satisfaction, quality, loyalty, value and expectation in service organization: an empirical research. POMS 15th Annual Conference. Cancun: POMS, 2004.

GONÇALVES FILHO, C; SOUKI, Gustavo. Relatório de pesquisa: comportamento do consumidor do curso de Engenharia de Telecomunicações. Universidade Fumec: Belo Horizonte, 2008. 
GONÇALVES FILHO, C.; GOMES, F. A.; SOUKI G.

Antecedents of Customer Loyalty: an Empirical Study of Cell Phone Market. POMS 19th Annual Conference. La Jolla: POMS, 2008

HAIR Jr., Joseph F. et al. Multivariate data Analysis. 5. ed. Upper Saddle River (NJ): Prentice Hall, 1998.

\section{INEP. Sinopses Estatísticas da Educação Superior:} Graduação. [2010]. Disponível em: <http://www.inep.gov. $\mathrm{br} /$ superior/censosuperior/sinopse/default.asp $>$. Acesso em: 21 jun. 2010.

JÖRESKOG, Karl G.; SÖRBOM, Dag. LISREL 7 A guide to the program and applications. 2. ed. Uppsala, Sweden. SPSS. 1989.

KLINE, R. B. Principles and practice of structural equation modeling. New York: The Guilford Press, 1998.

KOTLER, Philip; KELLER, Kevin Lane. Administração de marketing. 12. ed. São Paulo: Pearson Prentice Hall, 2006.

KOTLER, Philip. Administração de marketing: análise, planejamento, implementação e controle. 5. ed. São Paulo: Atlas, 1998.

KOTLER, Philip. Administração de marketing: a edição do novo milênio. 10. ed. São Paulo: Prentice Hall, 2000.

MARQUES, Licione Torres; BRASIL, Vinícius Sittoni. Validação de um modelo de lealdade do estudante com base na qualidade do relacionamento. In: ENCONTRO DA ANPAD, 32., 2008, Rio de Janeiro. Trabalhos Apresentados... Rio de Janeiro: Pontifícia Universidade Católica do Rio Grande do Sul, 2008. p. 16.

MARQUES, Licione Torres. Validação de um modelo de lealdade do estudante com base na qualidade do relacionamento. 2008, 120 f. Dissertação (Mestrado da Pontifícia Universidade Católica do Rio Grande do Sul - PUCRS) - Pontifícia Universidade Católica, Rio Grande do Sul , 2008. Disponível em: < http://tede.pucrs. br/tde_arquivos/2/TDE-2008-08-08T084932Z-1452/ Publico/403558.pdf>. Acesso em: 9 jun. 2010.
MARTINS, Jane M. D. Marketing educacional: um estudo sobre atributos e imagem das instituições de ensino superior. 2006, 157 f. Dissertação (Mestrado da Faculdade de Ciências Empresariais - FACE) - Universidade Fumec, Belo Horizonte, 2007. Disponível em: <http:/www. face.fumec.br/cursos/mestrado/dissertacoes/completa/ jane_maria_diniz_martins_luiz_antonio.pdf $>$. Acesso em: 6 jun. 2010.

MATHEUS, Zilda Maria. O comportamento do consumidor do ensino/formação por computador a partir da análise do modelo geral de HowardSheth. Universidade Anhembi Morumbi, maio de 2005, p. 1-8. Disponível em: < http://www.abed.org.br/ congresso2005/por/pdf/130tcf5.pdf>. Acesso em: 21 jun. 2010.

MELO, Gustavo H. O. O impacto das emoções geradas a partir de estímulos ambientais na satisfação de discentes de uma IES privada. 2009, 98 f. Dissertação (Mestrado, da Universidade Federal de Fortaleza - UNIFOR) - Universidade Federal de Fortaleza, 2009. Disponível em: <https://uol11.unifor.br/oul/ ObraBdtdSiteTrazer.do? method $=$ trazer\&obraCodigo $=79$ 983\&programaCodigo $=67 \#$ > . Acesso em: 10 jun. 2010 .

MELO, Gustavo H. O. et al.; O impacto das emoções geradas a partir de estímulos ambientais na satisfação de discentes de uma IES privada. In: ENCONTRO DA ANPAD, 33., 2009, São Paulo. Trabalhos

Apresentados... São Paulo: Universidade Federal de Fortaleza, 2009. p. 17.

NETEMEYER, R. G.; BEARDEN, W. O.; SHARMA, S. Scaling procedures: Issues and Applications. SAGE, 2003.

RIBEIRO, Vagner C. et al. Validação estatística da escala servqual em IES: uma análise fatorial confirmatória. In: XIII Semead - Seminários de Administração, 2010, São Paulo. XIII Seminários de Administração - Semead, 2010.

RICHARDSON, R. J. Pesquisa social: métodos e técnicas. São Paulo: Atlas, 1999.

RICHERS, Raimer. O enigmático mais indispensável consumidor: teoria e prática. Revista de

Administração, São Paulo, v. 19, p, 46-56, jul./set., 1984. 
SAMPAIO, D. O. et al. Um estudo comparativo sobre o comportamento do consumidor de automóveis novos. 2004. Disponível em: < http://www.ead.fea.usp.br/ semead/7semead/paginas/artigos\%20recebidos/marketing/ MKT76_-_Um_Estudo_comparativo_do_comp_consumid. PDF>. Acesso em: 20 jun. 2010.

SCHIFFMAN, Leon G.; KANUK, Leslie Lazar.

Comportamento do consumidor. 6. ed. Rio de Janeiro: LTC, 2000.

SHETH, Jagdish N.; MITTAL, Banwari; NEWMAN, Bruce I. Comportamento do cliente: indo além do comportamento do consumidor. São Paulo: Atlas, 2008.

\section{SOARES, Lucas, B. Antecedentes da lealdade de} clientes de serviços: um estudo empírico no setor de ensino superior. 2007, 118 f. Dissertação (Mestrado da Faculdade de Ciências Empresariais - FACE) Universidade Fumec, Belo Horizonte, 2007. Disponível em: <http://www.face.fumec.br/cursos/mestrado/ dissertacoes/completa/lucas_beraldo_soares.pdf $>$. Acesso em: 18 jun. 2010.

SOLOMON, Michael R. O comportamento do consumidor: comprando, possuindo e sendo. 5. ed. Porto Alegre: Bookman, 2002.

SOUKI, G. Q.; BERNARDES NETO, João.

Desenvolvimento e validação de uma escala para avaliação da qualidade percebida por estudantes de instituições de ensino médio. In: XXXI Encontro da ANPAD - EnANPAD, 2007, Rio de Janeiro. XXXI

Encontro da ANPAD - EnANPAD 2007, 2007.

TABACHNICK, B. G.; FIDELL, L. S. Using Multivariate

Statistics. 3. ed. New York: HarperCollins, 2001.

TERCI, Suzie. Você realmente sabe o que é comportamento do consumidor? Iniciação Científica, Cesumar, Maringá, v. 3, n. 2, p. 91-103, ago./dez. 2001. Disponível em: <http://www.cesumar.br/pesquisa/ periodicos/index.php/iccesumar/article/view/42/5>. Acesso em 17 jun. 2010.

TORRES, Ricardo. Ciência da computação. Portal Terra. Guia das profissões. [2010]. Disponível em: < http:// noticias.terra.com.br/vestibular/interna/0,,OI3014215EI11800,00-ciencias+da+ computacao.html>. Acesso em: 17 mar. 2010.
UNIVERSIDADE Federal de Minas Gerais (UFMG).

Ciência da computação. Departamento de ciência da computação.. Instituto de Ciências exatas (ICEx). [2010]. Disponível em: <http://www.dcc.ufmg.br/dcc/index.

php?option $=$ com_content $\&$ view $=$ article\&id $=88$ :informa coescursocc\&catid =48: cienciacomputacao\&Itemid $=73>$. Acesso em: 30 mar. 2010.

UNIVERSIDADE Anhembi Morumbi. Ciência da computação. [2010]. Disponível em: <http:// anhembi.br/publique/cgi/cgilua.exe/sys/start. htm?infoid $=125 \&$ sid $=11>$. Acesso em: 28 mar. 2010.

UNIVERSIDADE Passo Fundo (UPF). Ciência da computação. (UPF). [2010]. Disponível em: <http:// www.upf.br/computacao/index.php?option $=$ com_cont ent\&view $=$ frontpage $\&$ Itemid $=1>$. Acesso em: 28 mar. 2010.

UNIVERSIDADE de São Paulo (USP). Ciência da Computação. Departamento de ciência da computação. Instituto de matemática a estatística. USP. [2010]. Disponível em: <http://www.ime.usp.br/webadmin/dcc/ grad>. Acesso em: 29 mar. 2010.

VEIGA, Ricardo T. Um exame empírico do modelo de conseqüências comportamentais da qualidade de serviços. 2000. 420p. Tese (Doutorado em Administração de Empresas) - Faculdade de Ciências Econômicas, Universidade Federal de Minas Gerais, Belo Horizonte. 2000.

VIEIRA, Valter Afonso. Comportamento do consumidor. Revista de Administração Contemporânea (RAC), Curitiba, v. 6, n. 3, set./dez. 2002.

VIEIRA, Valter Afonso. Comportamento do consumidor.

Revista de Administração Empresas (RAE). São Paulo, v. 2, n. 1, jan./jun. 2003. 